\title{
Does Culture Influence What and How We Think? Effects of Priming Individualism and Collectivism
}

\author{
Daphna Oyserman and Spike W. S. Lee \\ University of Michigan
}

\begin{abstract}
Do differences in individualism and collectivism influence values, self-concept content, relational assumptions, and cognitive style? On the one hand, the cross-national literature provides an impressively consistent picture of the predicted systematic differences; on the other hand, the nature of the evidence is inconclusive. Cross-national evidence is insufficient to argue for a causal process, and comparative data cannot specify if effects are due to both individualism and collectivism, only individualism, only collectivism, or other factors (including other aspects of culture). To address these issues, the authors conducted a meta-analysis of the individualism and collectivism priming literature, with follow-up moderator analyses. Effect sizes were moderate for relationality and cognition, small for self-concept and values, robust across priming methods and dependent variables, and consistent in direction and size with cross-national effects. Results lend support to a situated model of culture in which cross-national differences are not static but dynamically consistent due to the chronic and moment-to-moment salience of individualism and collectivism. Examination of the unique effects of individualism and collectivism versus other cultural factors (e.g., honor, power) awaits the availability of research that primes these factors.
\end{abstract}

Keywords: culture, individualism, collectivism, situated cognition, priming

Supplemental materials: http://dx.doi.org/10.1037/0033-2909.134.2.311.supp

In answer to the questions what is meant by culture and how does culture matter, cultural psychologists have argued both that culture matters to the extent that individuals living in different societies are likely to have differing experiences and, more ambitiously, that culture matters to the extent that a cultural perspective provides new insights into psychological processes (e.g., Bond \& Leung, in press; Triandis, 1996). In the current article we focus on one prominent path for operationalizing culture: individualism and collectivism (e.g., Hofstede, 1980, 2001; Kağıtçıbaşı, 1997; Kashima, Kashima, \& Aldridge, 2001; Oyserman, Coon, \& Kemmelmeier, 2002; Triandis, 1995, 2007). We examine the extent to which studies that shift the salience or accessibility of aspects of individualism or collectivism provide further insight into how culture matters, using meta-analysis as our summative technique. We ask first if these studies demonstrate theoretically relevant links between individualism or collectivism and core psychological constructs (values, self-concept, relationality, and cognitive processes) and second, what these studies can tell us about how

Daphna Oyserman and Spike W. S. Lee, Department of Psychology, University of Michigan.

In addition to the University of Michigan, we would like to acknowledge and thank our host universities during the first revision of this article; from December, 2006 to May, 2007 Daphna Oyserman was on sabbatical at the Hong Kong University of Science and Technology and Spike W. S. Lee was completing undergraduate studies at the Chinese University of Hong Kong.

Correspondence concerning this article should be addressed to Daphna Oyserman, Institute for Social Research, 426 Thompson Avenue, Ann Arbor, MI 48109-1248. E-mail: daphna.oyserman@umich.edu individualism and collectivism may operate within a society. We conclude by also noting what these studies cannot yet tell us and what further research needs to be done.

From a cultural psychological perspective, individualism and collectivism are constructs that summarize fundamental differences in how the relationship between individuals and societies is construed and whether individuals or groups are seen as the basic unit of analyses (for a review, see Oyserman, Coon, \& Kemmelmeier, 2002). Within individualism, the core unit is the individual; societies exist to promote the well-being of individuals. Individuals are seen as separate from one another and as the basic unit of analysis. Within collectivism, the core unit is the group; societies exist, and individuals must fit into them. Individuals are seen as fundamentally connected and related through relationships and group memberships. These differences between individualism and collectivism have been associated with different experiences and, arguably, have highlighted within- as well as between-society heterogeneity in the propensity to use some cognitive processes (e.g., assimilation or inclusion) more than others (e.g., contrast or exclusion; for broad theoretical process models see, e.g., Oyserman, Kemmelmeier, \& Coon, 2002; Oyserman \& Lee, 2007, in press).

We focus on individualism and collectivism because the literature focused on these constructs has produced important insights into psychological processes (for a review, see Oyserman, Coon, \& Kemmelmeier, 2002) and because many other identified cultural factors can be conceptually and empirically linked to these constructs (e.g., power, femininity; for a review, see Blondel \& Inoguchi, 2006). As outlined below, the extant cross-national literature demonstrates an association between individualism and 
collectivism and psychological outcomes of interest (values, selfconcept, relationality, cognitive processes) and suggests that culture influences both content (e.g., how one thinks about oneself) and process (e.g., whether the focus of perception is a salient figure or the relationship among figures). Evidence for the impact of individualism and collectivism comes from two sources: multinational studies and cross-national comparisons.

Multinational studies together provide converging support for the notion that countries differ to the extent that samples drawn from their citizenry endorse values relevant to individualism and collectivism, particularly because each multinational study involves independently developed samples and measures (Hofstede, 1980; Inglehart, 1990, 1997, 2000; Inglehart \& Baker, 2000; Schwartz, 1990; Schwartz \& Bilsky, 1987; Triandis, 1988, 1989, 1995). As an alternative to large-scale multinational studies, crossnational researchers often compare two countries on particular aspects of individualism and collectivism or on variables assumed to be associated with these constructs. Though each study involves fewer between-country comparisons, replication across studies and conceptual replication using different operationalizations of constructs add confidence to the validity of findings (see Oyserman, Coon, \& Kemmelmeier, 2002, for a review).

A meta-analysis of the cross- and multinational literatures supports the contention that countries differ systematically in individualism and collectivism. As assessed through scale values, North Americans are higher in individualism and lower in collectivism than people from many other countries, with patterns of results suggesting similarity among English-speaking countries (Oyserman, Coon, \& Kemmelmeier, 2002). Many of these studies also assessed differences in self-concept, relationships with others, and cognitive style, examining whether these differences are systematically associated with individualism and collectivism. A companion quantitative review of this literature found that differences in individualism and collectivism (directly assessed or inferred from prior research) are correlated with systematic differences in content of self-concept, nature of relationships with others and cognitive style (Oyserman, Coon, \& Kemmelmeier, 2002). Generally effects sizes are moderate-to-large for relationality and cognition and small for self-concept and values. Thus empirical integration validates some aspects of prior targeted reviews and suggests that at least two axes of culture, individualism and collectivism, demonstrate impressively systematic psychological implications.

Advances in the field also highlight gaps in knowledge. Of particular interest from a psychological perspective are processlevel gaps in causal reasoning. As Oyserman and colleagues (Oyserman, Coon, \& Kemmelmeier, 2002; Oyserman, Kemmelmeier, \& Coon, 2002) noted, evidence to date is supportive, not conclusive. The available pattern of between-country differences is not sufficient to convincingly argue that observed effects are due to individualism and collectivism. It is possible that other confounding variables are at work, influencing between-country differences. These confounding variables may be other cultural factors associated with individualism and collectivism, such as honor (e.g., Nisbett \& Cohen, 1996), power distance (e.g., Hofstede, 1980; or horizontality-verticality, Triandis \& Gelfand, 1998), or other noncultural factors such as gross national product (e.g., Inglehart \& Oyserman, 2004). Moreover, current data on betweencountry differences cannot disentangle competing representations of what is meant by culture. On the one hand, each society may have a culture that can be characterized as either individualistic or collectivistic (e.g., American society may be characterized as individualistic, Chinese society as collectivistic). On the other hand, each society may have a culture that includes both individualism and collectivism, with societies differing in the number of situations in which one or the other is cued (e.g., American society can often be characterized as individualistic but there are situations in which American society is better characterized as collectivistic, such as when national group membership is salient or threatened; Oyserman, Kemmelmeier, \& Coon, 2002).

Typically, solutions suggested for disentangling causality involve controlling for confounds in path analytic models (Cook \& Campbell, 1979). However, this procedure can be applied only if confounds are known and measurable. Given the large number of possible confounds at individual and societal levels and the difficulty in knowing which confounds are relevant and how to measure them, application of this method to the study of individualism and collectivism is likely to be problematic. Because the data at hand could support a variety of hypotheses, access to data that could better support causal reasoning is critical for the field.

Following the logic of experimentation, a first step toward demonstrating that cross-national effects are in fact due to individualism and collectivism would be to manipulate individualism and collectivism and demonstrate that between-country differences become systematically greater when the constructs of interest, individualism and collectivism, are made accessible and salient. Follow-up studies could examine effects when individualism, compared with collectivism, is primed and when different aspects of each construct are primed. Although still not conclusive, this would provide stronger evidence that the root of cross-national differences is in the salience and accessibility of individualism and collectivism as meaning-making constructs. Clearly, manipulating cultural variables by manipulating societal structures themselves is not possible.

Thus, a procedure is needed to identify causal effects when it is impossible to manipulate the independent variable of interest or to control confounding variables statistically. Such a procedure can be derived from Kelley's (1955) basic model (see also Taylor \& Fiske, 1978), which demonstrates that if a variable " $A$ " has a causal influence on an outcome of interest "O," this influence is more pronounced when the variable is the focus of the individual's attention (is salient and accessible) than when it is not. Moreover, in natural situations, in which sets of variables (A and B) are associated with each other as well as with outcomes, this strategy can be used to examine individual-level effects of social structure and social policy by demonstrating an effect of $\mathrm{A}$ on $\mathrm{O}$ when $\mathrm{A}$ is salient (see for example Schwarz \& Brand, 1983; Schwarz \& Strack, 1981).

Because this logic is directly relevant to studying culture's effects, we will outline it using Schwarz and Strack's (1981) study of the consequences of a German social policy (that political radicals not be employed in the civil service) on political expression. Simply showing a correlation between willingness to express political views $(\mathrm{O})$ and desire for civil service employment $(\mathrm{A})$ in the wake of the law would not be sufficient to demonstrate a causal effect because other unknown structural or personal factors (B) may influence who is interested in applying for these jobs. To show the relationship between $\mathrm{A}$ and $\mathrm{O}$, a way of manipulating the 
salience of A (but not other factors) was needed. Schwarz and Strack (1981) assumed that a set of variables (labeled C) exists that would make A salient and chose one, salience of the employment policy, as their $\mathrm{C}$ variable. They had a random half of sampled students fill out a survey in which the employment policy was mentioned (prime condition). The other half of sampled students were not asked to fill out this survey (no-prime condition). A few hours later, an ostensibly separate event occurred. Students were approached in their dorms and asked to sign a moderately worded petition asking the government to focus effort on reducing air pollution. Students were given a copy of the petition with a single signature line so that they could not gauge how many others had also signed. Almost all of the nonprimed students agreed to sign, whether or not they wanted a civil service job. However, among the primed students, those who wanted a civil service job were significantly less likely to sign the petition. The experiment supported the presumed relationship between the social policy (A) and political activity $(\mathrm{O})$ when the policy was salient $(\mathrm{C})$ among those who believed they might be affected.

As noted by Schwarz and Strack (1981), the experiment does not prove that other social structural or personal factors are not involved, because these factors may simultaneously have been cued, but it does provide support for the hypothesis that the policy itself had an effect (even if this effect occurs in the presence of confounds and other contributing factors). Because the effect occurred only when the policy was primed, the study supports the notion that it was the variable of interest (A), not the supposed confounds alone (B), that had an effect. The underlying logic of this approach can be applied in thinking about culture's influence on psychological outcomes of interest. Here too, the assumption is that the impact of societal-level variables, individualism and collectivism, can be studied by manipulating the subjective salience of aspects of these variables, and that what is made salient represents an aspect of the underlying class of variables relevant to each construct. The assumption is that individualism and collectivism each influence outcomes when salient.

Although manipulating societal structures (e.g., school systems) assumed to be consequences of individualism and collectivism is not possible, it is possible to manipulate the accessibility or salience of aspects of individualism and collectivism. Individualism and collectivism are more likely to influence judgments and behaviors when salient and accessible than otherwise. Although manipulation of salience has not been a typical part of the crossnational literature on culture, the idea that contexts activate cultural knowledge is well represented in the literature. For example, Liu (1986) articulated the idea that Chinese educational contexts can make salient procedural knowledge about how to engage with others and how to go about learning. Triandis and Trafimow (2001) identified a number of situational factors, such as whether one is with in- or out-group members, the size of the in-group one is with, and whether in-group norms have been cued, that are likely to cue collectivism. When collectivism is cued, aspects of one's self-concept related to one's public image should become salient, whereas when individualism is cued, aspects of one's self-concept related to one's private self-evaluation should become salient.

More generally, by thinking about culture's influence on individuals as mediated by the sense individuals make of their everyday contexts, it becomes possible to use advances in social cognition research as tools to unpack the process through which culture influences individuals. Social cognition as a field has highlighted that human judgment and behavior are influenced by what comes to mind at the moment of judgment and how this content is interpreted (Bargh, 1984, 2006; Bargh, Bond, Lombardi, \& Tota, 1986; Higgins, 1989, 1996; Higgins \& Bargh, 1987; Higgins, Rholes, \& Jones, 1977; Srull \& Wyer, 1978, 1979). This salient and accessible information can be content, process, or goal oriented (Förster, Liberman, \& Friedman, 2007). Content provides meaning; procedures tell us how to process information to make sense of experience (Schwarz, 2002, 2006); goals direct our actions by representing desired end-states (Förster et al., 2007). Content, procedures, and goals can be cued via priming techniques.

In the lab, priming typically involves having participants engage in a series of tasks. Participants are not made aware of the researchers' intent to influence them. Unbeknownst to participants, concepts, procedural knowledge, and goals cued by the first task (prime) carry over to subsequent tasks. This spillover effect can be studied by comparing groups exposed to different primes. Priming experiments typically involve simple between-subjects designs that ask how engaging in one task (prime or control) influences responses to an allegedly unrelated subsequent task (outcome).

Priming activates mental representations that then serve as interpretive frames in the processing of subsequent information (Bargh \& Chartrand, 2000; Higgins, 1996). When a concept is primed, other concepts associated with it in memory are also activated (Neely, 1977). When a cognitive style or mindset is primed, this activates a way of thinking or a specific mental procedure (Bargh \& Chartrand, 2000). Mindset priming involves the nonconscious carryover of a previously stored mental procedure to a subsequent task.

Priming studies can create an experimental analogue of chronic between-society differences by temporarily focusing participants' attention on culture-relevant content (values, norms, beliefs, and attitudes), culture-relevant goals, and cultural-relevant cognitive styles. By comparing responses after individualism or collectivism is primed with hypothesized or documented between-society differences, researchers can examine the extent to which psychological differences between members of different societies are actually due to the primed active ingredients of individualism or collectivism. By operationalizing and priming other cultural factors (e.g., power distance), researchers can test for the competing influences of individualism, collectivism, and other relevant factors. Experiments also provide the possibility of studying whether effects associated with one society can just as well occur in another when primed in another society. For example, if participants from the U.S. and participants from China are assumed to differ in average levels of individualism, does priming individualism in China result in responses similar to nonprimed responses in the U.S., and does priming collectivism in the U.S. result in responses similar to nonprimed responses in China?

This line of reasoning suggests that it is possible to study cultural influences by examining differences in judgments and behavior when individualism is made accessible or salient compared to when collectivism is made accessible or salient or that it is possible to control circumstances. If individualism and collectivism have the effects on self-concept, relationality, and cognitive processes described in the cross-cultural literature, then effects should be stronger when elements of individualism and collectiv- 
ism are made accessible or salient. Because the cross-national literature contrasts results between collectivism and individualism, a straightforward test would be to make individualism salient for a random half of participants and collectivism salient for a random half of participants and see if the two groups differ along the lines proposed by the cross-national evidence. A second question is whether cross-national differences can be better attributed to individualism, to collectivism, or to both. To examine this question, we must compare individualism-primed and collectivism-primed participants to a control condition; studies comparing a single prime (individualism or collectivism) to control can be used to assess the robustness of conclusions drawn from studies including both primes.

This challenge has been taken up in an emerging body of studies that primes aspects of individual and collective self and examines the extent to which this produces expected effects on salient values, salient content of self-concept, salient ways of relating to others, and salient cognitive style. In the current article, we report on our systematic meta-analysis of this literature.

\section{Hypotheses}

Five specific hypotheses about the effects of individualism and collectivism can be derived from the pattern of results from crossnational studies. For ease, each hypothesis assumes a contrast between salient or accessible individualism and salient or accessible collectivism (or a no-prime control). When individualism is primed then (a) endorsement of individualistic values will increase and endorsement of collective values will decrease; (b) working self-concept will include more emphasis on attributes and unique traits and less emphasis on social or relational identities; (c) closeness and obligation to in-group others and sensitivity to their needs and goals will decline; (d) well-being will be associated more with happiness, self-fulfillment, and personal success and less with fulfilling social obligations and commitments, providing reflect-able glory for in-group members or basking in the reflected glory of other in-group members; and (e) accessible processing strategies will focus more on contrasting, pulling-apart, distinguishing-and-separating and less on assimilating, connecting-and-integrating, or compromising.

Following the logic of experimentation, finding that priming individualism and collectivism produces results in these patterns will support the hypothesis that individualism and collectivism influence values, self-concept, relationality, bases of well-being, and cognitive style. Because effects are based on experimental manipulation, they can be interpreted as showing effects of individualism and collectivism above any confounding factors or correlates. Results cannot provide insight into the relative effect of individualism and collectivism compared to other culture factors or other potential confounds; rather they provide an estimate of the total effect of primed features of individualism and collectivism without apportioning the relative contributions of individualism and collectivism. To assess their effects relative to other factors, we must introduce these other factors into the design. Such data are not yet available, so the relative effect of individualism and collectivism versus other factors cannot be assessed.

Separately examining the pattern of results when primed individualism and primed collectivism are each compared to control will provide insight as to whether effects are due to individualism, collectivism, or both. A caveat should be noted here. Comparison to control is a standard element of experimental design. However, in the case of research on culture, priming all participants rather than comparing to "control" reduces the ambiguity of inference, because we cannot infer that the "control" participants are not using an individualism or a collectivism culture-relevant frame at all. Thus, comparison of control to primed individualism or primed collectivism should provide a conservative estimate of relative contribution, because "control" participants should be assumed, on average, to be influenced by chronically salient cultural constructs (e.g., individualism for Americans, collectivism for Chinese).

Priming Individualism and Collectivism: A Meta-Analysis

\section{Method and Sample}

An initial examination of the individualism and collectivism priming literature suggested that a number of priming tasks have been used. We conducted a cited references search to January 1, 2005 using the Version 3.0 ISI Web of Knowledge electronic database to retrieve English-language articles that cited at least one of these source priming articles: Brewer and Gardner (1996) or Gardner, Gabriel, and Lee (1999; pronoun circling task); Trafimow, Triandis, and Goto (1991; Sumerian warrior story; similarities vs. differences with family and friends task [SDFF]); and Srull and Wyer (1979) or Chartrand and Bargh (1996; scrambled sentence task). No key source article for subliminal priming or language priming tasks was found, so for each of these latter primes we did a keyword search in PsycINFO. For subliminal priming the keywords were subliminal* and (cultur* or self). For language priming the keywords were language* and (cultur* or self) and ( prime* or priming or vehicle* or agent* or activat*). We followed this up with examination of reference lists. Unpublished studies cited in the retrieved articles were requested from authors, resulting in one additional study (Adaval \& Cho, 2006). Articles describing a particular social identity (e.g., "being a member of your university"; Gaertner, Sedikides, \& Graetz, 1999) were excluded because including all studies priming any social identity would have dissipated the current focus on the impact of priming individualism and collectivism.

We focused our meta-analysis on the 67 studies $(6,240$ participants) that primed both individualism and collectivism and assessed effects on values, relationality, self-concept, well-being, and cognition. Each of these studies is summarized in Appendix A. To increase usability of this summary, we created a nested hierarchy. Studies are summarized by outcome, within outcome by region, within region by priming task, and within priming task alphabetically by author name (see Appendix A, Tables A1-A5) . A total of 19 studies are listed more than once due to the following reasons: more than one outcome was assessed $(n=10)$, more than one priming task was used $(n=4)$, or more than one ethnicity or region of the world was included $(n=10)$.

A subset of these 67 studies $(n=14 ; 1,664$ participants $)$ included both the cultural-syndrome primes and comparison to control (Briley \& Wyer, 2001, Study 2; Gardner et al., 1999, Study 2; Kemmelmeier, 2003, Studies 1-2; Kühnen, Hannover, \& Schubert, 2001, Studies 2 \& 4; Lockwood, Dolderman, Sadler, \& Gerchak, 2004, Study 2; Stapel \& Koomen, 2001, Studies 1, 2, \& 5; Trafimow, Silverman, Fan, \& Law, 1997; Trafimow \& Smith, 
1998; Utz, 2004a, Study 1; van Baaren, Maddux, Chartrand, de Bouter, \& van Knippenberg, 2003, Study 2). We used this set of studies to draw inferences as to the relative size of effect when priming individualism and collectivism. The comparison-tocontrol studies are not presented as a separate Appendix because these studies are already summarized in Appendix A.

A final analysis focused on studies (2,986 participants) that were not included in the main meta-analysis for one of two reasons. Either the study used a prime that was difficult to interpret ( $n=$ 11 ) or data were reported only for one priming task $(n=21)$. Both of the additional values-focused studies used primes that were difficult to interpret (Bovasso, 1997; Briley \& Wyer, 2001, Study 3 ), as did 3 of 7 self-concept focused studies (Chen, Chen, \& Shaw, 2004, Study 2; Gaertner et al., 1999, Study 3; Kanagawa, Cross, \& Markus, 2001), 4 of 16 relationality-focused studies (Wit \& Kerr, 2002, Studies 1-3; Mandel, 2003, Study 2), and 2 of 8 cognitive-process focused studies (Briley \& Wyer, 2002, Study 6; Wenzel, 2002, Study 3). ${ }^{1}$ Nine studies employed only an individualism priming task (Finlay \& Trafimow, 1998; Holland, Roeder, van Baaren, Brandt, \& Hannover, 2004, Study 1; Mussweiler \& Bodenhausen, 2002, Study 3; Stapel \& Koomen, 2001, Studies 3-4; Stapel \& Tesser, 2001, Studies 3-4; Utz, 2004a, Study 2; van Baaren et al., 2003, Study 1). Twelve studies employed only a collectivism priming task (Brewer \& Gardner, 1996, Studies 1-3; Chen et al., 2004, Study 1; Crisp, Hewstone, Richards, \& Paolini, 2003; Fitzsimons \& Kay, 2004, Studies 1-4; Reed, 2004, Study 1; Vorauer \& Cameron, 2002, Studies 3 \& 5).

Supplemental Appendix B, Tables B1-B4, summarizes these 32 studies, following the same ordering method used for Appendix A. Our rationale for using these studies in a final meta-analysis was to ascertain the extent to which our initial estimates were robust to variation in design. Taken alone, studies in this set of analyses might be considered weaker evidence of the effects of individualism and collectivism. However, validity of any found relationships is increased if the pattern of effects is robust to differences in design. Therefore, to the extent that results are stable across main and supplementary analyses, confidence in the results should increase.

The total number of 67 studies in the main meta-analysis excludes 3 studies dropped due to insufficient statistical information from the original authors (Clayton, 2000, Study 2; Mandel, 2003, Study 1 pretest; Ybarra \& Trafimow, 1998, Study 3). Except for these 3 studies, data quality overall was satisfactory with little missing information; authors were able to provide design and statistical information where insufficient detail was available in the published report. Where data were not available from the author but estimable, we estimated effect sizes on the basis of reported descriptive and inferential statistics with the help of a computer program (Johnson, 1993). Whenever possible, we estimated standard deviations only from the portion of a study's data that was used to compute the effect size.

\section{Individualism and Collectivism Priming Tasks (Independent Variables)}

Individualism priming tasks focused on the individual self (e.g., using $I$ as a prime), on specific aspects of the individual self (e.g., the self as different or unique), or on difference and separateness more generally (e.g., using separate as a prime). Collectivism priming tasks focused on the collective self (e.g., using we as a prime), on specific aspects of the collective self (e.g., similarity with or obligation to family, friends, and larger groups such as teams), or on connection and integration more generally (e.g., using connect as a prime). This allowed us to categorize levels of collectivism primed as either relational-level, group-level, or both.

\section{Group-Level Collectivism}

Two priming tasks attempted to explicitly evoke group focus in their collectivism primes by instantiating a group in the lab or by having participants imagine that they were part of a team (or alone) or that their family (or they themselves) was consuming grape juice. Broadly speaking, these primes may be considered minimal group primes, congruent with classic social identity research (Tajfel, 1982, 2001; Tajfel \& Forgas, 2000; Tajfel \& Turner, 2004). Focus on groups connects with Hofstede's (1980) focus on the workplace as a nexus of cultural values and with the crossnational literature examining collectivism via preference for working in groups (see Oyserman, Coon, \& Kemmelmeier, 2002). These were the least common priming tasks we found; only $18 \%$ of studies used one of these primes.

Group instantiation. Three studies used this prime (Briley \& Wyer, 2002, Studies 1-3). Collectivism priming involved group formation and intergroup competition (being seated at five-person tables, working as a group, giving the group a name, being told that points were rewarded to the group, and competing against other groups). Individualism priming involved performing the task individually and being seated at single-person desks separated by partitions.

Group imagination. Eight studies used this prime (Aaker \& Lee, 2001, Study 2 pretest \& Studies 2-4; Lee, Aaker, \& Gardner, 2000, Studies 2-5). Collectivism (individualism) priming involved

\footnotetext{
${ }^{1}$ Bovasso (1997) presented what appears to be a mix of social and personal foci in an individualism prime. Briley and Wyer (2002, Study 6) used cultural icons from one's own country (presumably a collectivism prime) and cultural icons from another country; their task is ambiguous because the other country prime may be another collectivism prime (if the icons are perceived as representing an out-group), neutral (if the icons are perceived as simply irrelevant), or an individualism prime (if the icons are seen to represent individualism). Chen et al. (2004, Study 2) had a dual prime - they made social identity salient in addition to priming individualism or collectivism. Gaertner et al. (1999, Study 3) used a minimal group as a collectivism prime, which seems irrelevant given that the dependent variable was anger at insult to in-group versus self. Kanagawa et al. (2001) had the Twenty Statements Task (TST) read by a professor versus in a group versus on audiotape; it is not clear how to conceptualize this in terms of individual versus collective priming. Mandel (2003, Study 2) used nonparallel video clips (Family Man vs. a tutorial on resume writing) as primes. Wenzel (2002, Study 3) used a minimal group team-focused prime (participants were told that they should compete either with other participants or as a team against another team; prior to engaging in the activity, they were asked to think about and write down either differences or similarities between themselves and the other players on their team). Wit and Kerr (2002, Study 1-3) had participants engage in allocation tasks in which they were sometimes solo agents, sometimes included or excluded from a group, and sometimes in a smaller or larger group. All of these distinctions are interesting but difficult to reconceptualize in individualism versus collectivism prime terms.
} 
imagining oneself competing on a tennis team (in a singles match) or imagining one's family (oneself) consuming grape juice.

\section{Relational-Level Collectivism}

Two of the primes focused on priming relational-level collectivism. One or the other of these primes is used in almost half $(46 \%)$ of all priming studies we located.

Similarities and differences with family and friends task $(S D F F)$. Trafimow et al. (1991, Study 1) developed this task. To prime individualism the instructions were as follows: "For the next two minutes, you will not need to write anything. Please think of what makes you different from your family and friends. What do you expect yourself to do?" To prime collectivism the instructions were as follows: "For the next two minutes, you will not need to write anything. Please think of what you have in common with your family and friends. What do they expect you to do?" (p. 651; emphasis added). As noted in the italicized text, the focus was on others with whom one has a close relation.

Pronoun circling task. Brewer and Gardner (1996) developed an initial version of this task that contrasted we with they. This work was refined by Gardner et al. (1999), who developed the initial form of the pronoun circling task comparing a focus on $I$ (as well as me and $m y$ ) with a focus on we (as well as us and ours) where the "we" are friends who go together into the city. Specifically the task is to circle personal singular or plural pronouns in a paragraph. A number of paragraphs have been used like the following:

We go to the city often. Our anticipation fills $u s$ as we see the skyscrapers come into view. We allow ourselves to explore every corner, never letting an attraction escape us. Our voice fills the air and street. We see all the sights, we window shop, and everywhere we go we see our reflection looking back at $u s$ in the glass of a hundred windows. At nightfall we linger, our time in the city almost over. When finally we must leave, we do so knowing that we will soon return. The city belongs to $u s$.

The italics show the relational collectivism prime; these are replaced by $I, m y$, and mine in the individualism prime. The paragraphs have been modified to describe a day on the farm, a day at the beach, a visit to a restaurant, and other events (see Haberstroh, Oyserman, Schwarz, Kühnen, \& Ji, 2002; Kühnen \& Oyserman, 2002; Oyserman, Sorensen, Reber, Sannum, \& Chen, 2008). Activating the concepts "I" and "we" should activate relevant values, ways of describing oneself, and engagement with others. The paragraphs used in this task all have in common going to or being at a specific place either alone or with a group. The group is assumed to be small enough to go together to the place-one hardly imagines going to the city with all the members of one's racial/ethnic, religious, or national group; one is more likely to imagine going with a few close others.

\section{Both Relational- and Group-Level Collectivism}

Three collectivism primes focused on both group- and relational-levels of collectivism. Two of these primes, scrambled sentence tasks (Srull \& Wyer, 1979) and subliminal priming, are standard in the general priming literature. In the third prime, participants imagined themselves in the shoes of a Sumerian warrior, making choices in part due to group (tribe) membership as well as family concerns. This prime is similar to the SDFF prime in that instructions simply ask participants to imagine the situation. Thirty-six percent of studies used one of these primes.

Scrambled sentence task. Scrambled sentence priming tasks are tasks in which words are presented that the participant is to unscramble to create a meaningful sentence. To prime individualism, the words I, me, mine, distinct, different, competitive, own, free, unique, dissociate, assertive, unusual, autonomy, alone, apart, autonomous, detached, different, dissimilar, distinct, diverge, independence, individual, isolate, separate, solitude, split, unique, and self-contained were used. To prime collectivism, the words we, us, ours, join, similar, alike, share, cooperative, agreeable, help, group, respect, partnership, together, team, support, others, attached, alliance, closeness, cohesive, connection, inseparable, interdependence, intimate, joint, merged, overlap, similar, shared, together, union, and friendships were used.

Subliminal priming. Subliminal priming involves the presentation of target words or pictures at a speed too fast (e.g., $35 \mathrm{~ms}$ ) for conscious processing. Only one study utilized this paradigm in the individualism and collectivism priming literature. Oishi, Wyer, and Colcombe (2000, Study 3) included in their priming task the following words: own, mine, compete, I, me, individual, distinct, and free (vs. share, ours, cooperate, us, we, group, same, and team). Given that we had only one example of subliminal priming, we were forced to include this category in our tertiary "miscellaneous other primes" category (described below).

Sumerian warrior story. Trafimow et al. (1991, Study 2) developed this task. Instructions read as follows: "We would like you to read a couple of paragraphs on the following page. After reading these paragraphs, you will be asked to make a judgment about the main character" (p. 652). The participant is then given a lengthy text to read that focused on choosing a warrior on the basis of either individual talent or tribe membership and family considerations.

\section{Language Itself as a Prime}

Ten studies primed individualism or collectivism with language rather than a task (Bond \& Yang, 1982; Kemmelmeier \& Cheng, 2004; Marian \& Kaushanskaya, 2004; Ralston, Cunniff, \& Gustafson, 1995; Ross, Xun, \& Wilson, 2002; Tavassoli, 2002; Trafimow et al., 1997; Watkins \& Gerong, 1999; Watkins \& Regmi, 2002; Yang \& Bond, 1980). Bilingual participants were randomly assigned to English or another language (i.e., Chinese Cebuano, Nepali, and Russian). The assumption is that English carries with it knowledge about American or Anglo-Saxon culture and so evokes individualism, whereas other non-Western languages carry with them knowledge about a home culture assumed to be more collectivist.

\section{Miscellaneous Other Primes}

Seven studies (including the single subliminal priming study; Oishi et al., 2000, Study 3) were included in a tertiary category of clearly described priming tasks that could not be categorized. In Aaker and Lee (2001, Study 1 pretest \& Study 1), participants read a Web site advertisement focusing on personal or family-oriented aspects of a product. In Mandel (2003, pilot study \& Study 1), 
participants recalled a personal experience of purchasing something that benefited the self or family and/or friends. ${ }^{2}$ In Stapel and Koomen (2001, Study 2), participants wrote a paragraph with specific pronouns (I, me, myself, and mine or we, our, ourselves, and ours) and words (unique, special, and unusual or together, integrate, and harmony). Wenzel (2002, Study 2) used a mix of group instantiation and SDFF. To prime collectivism (individualism), participants played a game as a group (individually), sat around the same (separate) table, used a shared (separate) response sheet, and were told to compete with other groups (individuals), to give the group (each player) a name, and to think about and write down similarities (differences) to other players (SDFF).

\section{Outcomes (Dependent Variables)}

To conduct the analyses, we divided studied outcomes into categories as summarized below. As in any meta-analysis, our operationalizations of the constructs of interest are limited by the measures used in the source studies.

\section{Values}

Categorized as values were items from the Schwartz (1992), Triandis (1995), or Triandis, McCusker, and Hui (1990) individualism and collectivism scales as well as measures of Chinese social beliefs (e.g., "If one's teacher or superior has done something wrong, the student or subordinate should not disclose it to anybody, and tolerate it," "The ways in which schools discipline students nowadays are overly lenient"; Yang \& Bond, 1980, p. 415) and other value judgments (e.g., endorsement of proverbs, Briley \& Wyer, 2002, Studies 1 \& 3; acceptance of euthanasia, Kemmelmeier, Wieczorkowska, Erb, \& Burstein, 2002, Study 3).

\section{Self-Concept}

We categorized as self-concept content the coding of the Twenty Statements Task (TST, an open-ended self-concept measure; Kuhn \& McPartland, 1954) and its variants, as well as items from the Leung and Kim (1997) and Singelis (1994) SelfConstrual Scales. TST studies typically provided content coding of the proportion of responses focused on "private" self-concept (e.g., traits, abilities, physical descriptors, or attitudes) and proportion of responses focused on relational (e.g., role in a friendly or romantic relationship) and/or collective (e.g., membership in social, ethnic, or religious groups) self-concept content.

\section{Relationality}

We coded four variables as relevant to relationality: social obligation, perceived social support from others, social sensitivity, and prosocial orientation. We also included more specific operationalizations such as the choice to sit closer to a target other.

\section{Well-Being}

We coded mood (Gardner, Gabriel, \& Hochschild, 2002, Study 2; Ross et al., 2002), state emotion (Lee et al., 2000, Study 5), and life satisfaction (Oishi et al., 2000, Study 3) as well-being.

\section{Cognition}

Measures of procedure (e.g., inclusion-exclusion, assimilationcontrast, connect vs. pull apart, and prevention-promotion), whether in the context of social judgment tasks, social comparison tasks, or nonsocial judgments, were all categorized as cognition.

\section{Other Characteristics of the Database}

\section{Language}

Excluding studies where language itself was the prime, the languages English, German, Dutch, and Chinese were used.

\section{Region and Country}

Three regions and eight countries were involved: North America (the U.S., $n=36$; Canada, $n=2$ ), Southeast Asia (Hong Kong, $n=18$; Nepal, $n=1$; the Philippines, $n=1$; Singapore, $n=1$ ), and Western Europe (Germany, $n=9$; the Netherlands, $n=6$ ).

\section{Race/Ethnicity}

Three U.S. studies (Gardner, Gabriel, \& Dean, 2004; Oishi et al., 2000, Study 3; Trafimow et al., 1991, Study 1) explicitly included European heritage and other heritage (primarily Asian) participants and used this distinction in their analyses. However, most studies did not provide explicit information about participants' racial/ethnic heritage. It is unclear if studies did not include racial/ethnic minority participants or if racial/ethnic minority participants were included but sample sizes were too small for subgroup analyses. Unless otherwise specified, we assumed race/ ethnicity to be the majority group in the country (e.g., German heritage in Germany).

Given these limitations, ethnic/national heritage analyses compared three groups: Europeans and those of European heritage (Germans, Dutch, and Anglo-Saxon or European heritage North Americans), those of Asian heritage living in North America, ${ }^{3}$ and those of Asian heritage living in Asia (Hong Kong Chinese, Singaporeans, Nepalis, and Filipinos). This categorization excluded only two studies (Marian \& Kaushanskaya, 2004, involving Russian American immigrants; Trafimow \& Smith, 1998, involving Native Americans). We term these comparisons "by region" in subsequent analyses.

\section{Gender}

Only one third (37\%) of studies included gender in the statistical analyses; when gender was not included in analysis, the gender of participants was sometimes omitted entirely from study description. It is possible that gender was not studied due to imbalanced cells or was studied only as a fallback when no overall priming effect was found.

\footnotetext{
${ }^{2}$ This information is from Study 1 only; the pilot study was included in this category although we were unable to obtain information about the priming task for the pilot study from the text or the author.

${ }^{3}$ We coded Ralston et al.'s (1995) Chinese American participants as Asian American because this group referred to participants with a much larger exposure to the American culture, usually American-born with an Asian familial background.
} 


\section{Students as Participants}

All but five studies used only undergraduates as participants. Even these five were heterogeneous. Three presented only integrated results (Marian \& Kaushanskaya, 2004, undergraduate and graduate students; Trafimow et al., 1997, undergraduate and high school students; Trafimow \& Smith, 1998, undergraduate students and adults), and two used only non-undergraduates (Kemmelmeier \& Cheng, 2004, middle school students; Ralston et al., 1995, managers).

\section{Limitations of the Current Data}

As is often the case in psychological research, studies focused on undergraduates, sample information was limited, and in this case, even gender information was mostly omitted. Similar to the cross-national literature on culture, not all societies were equally represented. Of the 67 studies entered into the current metaanalysis, 36 were conducted in the U.S., and 44 were conducted in English (including studies conducted in Hong Kong). Studies not conducted in English were in German ( 9 studies, in Germany), in Dutch (5 studies, in the Netherlands), or in Chinese (1 study, in Hong Kong), and 10 studies used language itself as the prime. Most studies involved priming in a single country. However, 8 studies either directly compared data from within-country priming with a between-country comparison (Haberstroh et al., 2002, Study 2) or compared priming results in two countries (Aaker \& Lee, 2001, Study 2 pretest \& Study 2; Briley \& Wyer, 2001, Study 4; Gardner et al., 1999, Study 2; Lee et al., 2000, Studies 3-5). Results from these studies were congruent with the pattern of results found in studies involving only within-country priming, providing support to the validity of individualism and collectivism priming.

\section{Computation and Analysis of Effect Sizes}

\section{Direction and Size of Effects}

For ease of interpretation, effects that supported our hypotheses were coded and reported as positive effects; effects that did not support our hypotheses were coded and reported as negative. We interpret effect sizes following Cohen (1988): When $d<0.4$, effects are described as small; when $0.4<d<0.7$, effects are described as moderate; and when $d>0.7$, effects are described as large.

\section{Computation of Effects}

We computed and analyzed weighted mean effect sizes (overall effects) following Rosenthal (1995) with the aid of Comprehensive Meta-Analysis 2.0 (Biostat, 2005). Fixed effects models are used, given our interest in testing the effects of the particular primes in current use (rather than testing effects as if they represented a sampling of all possible primes).

Weighted mean effects are the mean difference between the individualism and collectivism priming conditions divided by the pooled standard deviation (the $g$ statistic) and weighted by the reciprocal of $g$ 's variance. This approach gives more weight to more reliable effect sizes (characterized by smaller variances; Hedges \& Olkin, 1985; Johnson \& Eagly, 2000; Lipsey \& Wilson, 2001). Comprehensive Meta-Analysis 2.0 (Biostat, 2005) converted $g$ to $d$, computing 369 effect sizes. In most cases (325 effect sizes or $88 \%$ of the total), calculation was based on means, standard deviations, and cell sizes. In the remaining $12 \%$ of cases, effect sizes were calculated from means, cell sizes, $F$ statistics, $t$ statistics, or $Z$ scores ( 28 effect sizes); from chi-square statistics and sample sizes ( 8 effect sizes); from rates and sample sizes (4 effect sizes); from means, standard deviations, sample sizes, and correlations between within-participants variables (3 effect sizes); or from sample size and $p$ value (1 effect size).

As a conservative estimate and so as not to violate independence assumptions, we first computed a single mean effect of priming for each study. For studies with multiple outcomes, multiple primes, or multiple participant groups, the overall study-level effect size and standard error were the weighted mean of within-study effect sizes and its corresponding standard error.

Even if the authors reported no effects or no significant effects, we computed effect sizes if they reported sufficient statistical information; otherwise we used the most conservative estimate and assigned an estimate of $d=0.00$, one-tailed $p=.50, Z=0.00$ (Rosenthal, 1995).

\section{Computation of Homogeneity Coefficients}

Two $Q$ homogeneity statistics were computed: $Q$ betweengroups and $Q$ within-groups. The $Q$ within-groups homogeneity coefficient was used to assess whether the estimated effect sizes we found in our sample of individualism and collectivism priming studies could be used as a population estimate. If this coefficient is not significant, generalization from sample to population is possible; if significant, generalization from sample to population is not warranted. The $Q$ between-groups homogeneity coefficient was used to assess whether effects were homogeneous or heterogeneous between groups (e.g., across different priming tasks). Significant $Q$ coefficients point to heterogeneity, and moderator analyses can be used as a follow-up to pinpoint the source of heterogeneity. We outline our moderator analyses below.

\section{Moderator Analyses}

Because priming provides a simplified analogue to the complexity of natural settings, it is important to assess whether extraneous factors (e.g., sample characteristics, operationalization of dependent variables) significantly moderated effects. Moderator effects were computed by specifying them as multiple within-study effects in Comprehensive Meta-Analysis 2.0 (Biostat, 2005). For example, to calculate gender effects, we treated the male and female data from each study as separate studies to obtain an overall effect of culture priming on male participants and an overall effect of culture priming on female participants. This approach does not affect accuracy of effect size estimates but may inflate standard errors, given that within-study effects are not necessarily independent assessments. Therefore, statistical significance tests comparing levels of each moderator should be considered conservative (Biostat, 2005).

\section{Meta-Analytic Results}

\section{Main Effects}

We found an effect of priming on values, self-concept, relationality, well-being, and cognitive style. As summarized in the first column of Table 1, there was a significant overall priming effect 
Table 1

Effect of Priming: General Summary of Meta-Analytic Results

\begin{tabular}{lcc}
\hline \multicolumn{1}{c}{ Criterion } & All studies & $\begin{array}{c}\text { Excluding } \\
\text { anomalous studies }\end{array}$ \\
\hline & Central tendency & \\
No. of independent studies & 67 & 64 \\
No. of independent participants & 6,240 & 5,408 \\
Median no. of participants per study & 63 & 62 \\
Mean unweighted $d$ & 0.45 & 0.49 \\
Median effect size & 0.43 & 0.47 \\
Mean weighted $d\left(d_{+}\right)$ & 0.34 & 0.42 \\
No. of studies with effects in the hypothesized direction $(\%)$ & $57(85 \%)$ & $57(89 \%)$ \\
\hline
\end{tabular}

\begin{tabular}{lcc}
\hline & $57(85 \%)$ & \\
& & \\
$S D$ & Variability & \\
Maximum $d$ & 0.34 & 0.42 \\
$Q_{3}: 75$ th percentile $d$ & 1.43 & 1.43 \\
$Q_{2}:$ th percentile $d$ & 0.69 & 0.69 \\
$Q_{1}:$ th percentile $d$ & 0.43 & 0.47 \\
Minimum $d$ & 0.22 & 0.28 \\
Normal-based $S D=0.75\left(Q_{3}-Q_{1}\right)$ & -0.42 & -0.27 \\
& 0.35 & 0.31 \\
\hline
\end{tabular}

Significance and homogeneity testing

\begin{tabular}{lcc} 
Combined (Stouffer) $Z$ & $12.90^{* * * *}$ & $15.13^{* * * *}$ \\
$95 \%$ CI for $d_{+}$ & $0.29,0.39$ & $0.37,0.48$ \\
Standard error & 0.02 & 0.03 \\
Homogeneity $(Q)$ of $d$ s composing $d_{+}$ & $256.57^{* * * *}$ & $174.54^{* * * *}$ \\
\hline Interpretative data & & \\
Coefficient of robustness: $M / S D$ & 1.32 & 1.17 \\
Classic fail-safe & 3,495 & 3,954 \\
\hline
\end{tabular}

Note. The anomalous studies were Bond and Yang (1982), Lee et al. (2000, Study 5), and Yang and Bond (1980). The rationale for their exclusion is provided in the text. When effects are in the hypothesized direction, they are reported as positive; when in the opposite direction, they are reported as negative. Effect sizes were weighted by the reciprocal of variance. $d=$ effect size; $d_{+}=$mean weighted effect size; $Q=$ homogeneity of effect size coefficient; $\mathrm{CI}=$ confidence interval.

${ }^{* * * *} p<.001$.

(mean unweighted $d=0.45$, mean weighted $d=0.34, S D=0.34$, $S E=0.02,95 \%$ confidence interval $[\mathrm{CI}]=0.29,0.39)$ that differed significantly from a null effect $(d=0.00)$ in the hypothesized direction $(Z=12.90, p<.001)$. A graphic display of the spread of effect sizes (presented as a stem and leaf plot in Table 2) shows that most effects were in the small to moderate range of $d=$ 0.3 to 0.6 . Sensitivity analyses suggest that effects are robust; we used both Rosenthal's (1979) and Duval and Tweedie's (2000a, 2000 b) methods as summarized below. Rosenthal's fail-safe $N$ test suggests that an additional 3,495 null-effect studies would have to be found in order to bring the observed priming main effect to nonsignificance. Rather than ask how many studies would be needed to produce a null effect, Duval and Tweedie (2000a, $2000 \mathrm{~b}$ ) devised an approach that assumes any asymmetry in dis-

Table 2

Effect (d) of Priming Individualism and Collectivism Across 67 Studies: Stem and Leaf Display

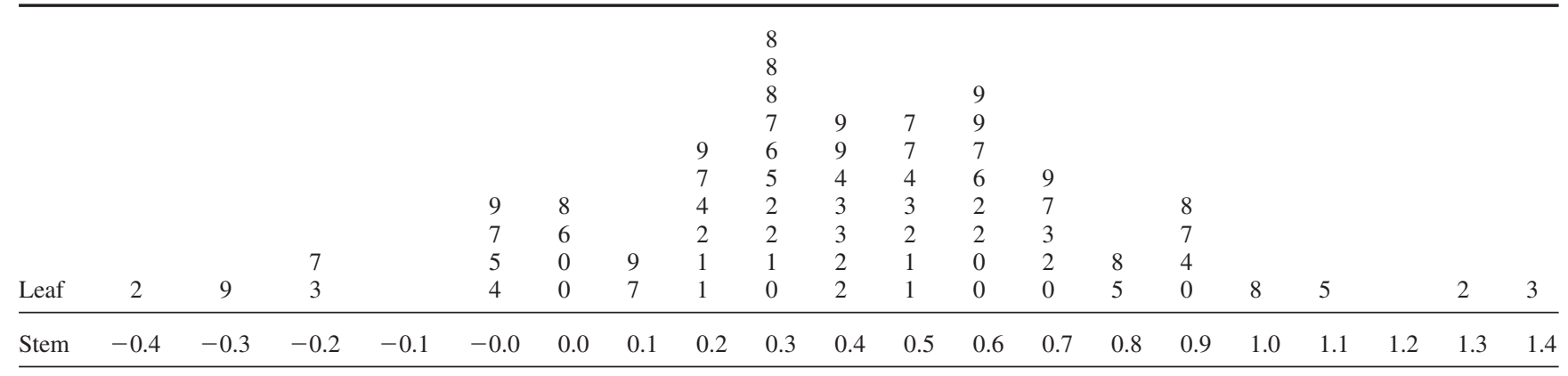




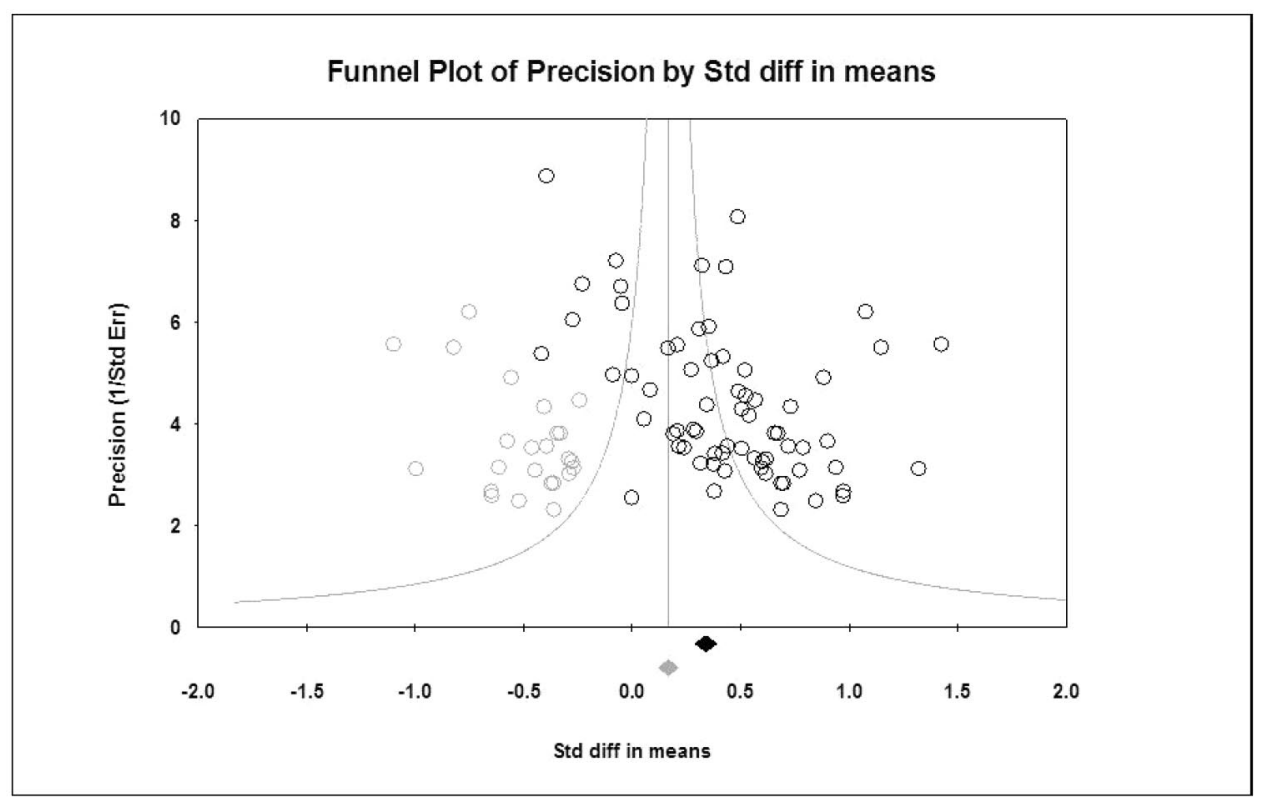

Figure 1. The relationship between inverse of standard error and effect size $(d)$ for each study, with or without the 24 imputed studies added by the fill analyses. Std Err = standard error; Std diff = standard difference. Black circles denote studies included in the meta-analysis; grey circles denote imputed studies. The black diamond represents the overall standard difference in means across studies included in the meta-analysis; the grey diamond represents the overall standard difference in means when imputed studies are included.

tribution of effects is due to publication bias and not due to the other factors (e.g., variable study quality, different outcome measures, or lack of effect size for nonsignificant findings) and refines the estimation procedure by imputing and filling in data to create a symmetric effect size distribution, producing a conservative effect size estimate (see Sutton, Song, Gilbody, \& Abrams, 2000). Employing their method, we created the funnel plot, including 24 imputed "missing" studies (see Figure 1). Even with this conservative approach, the adjusted effect remains significant (mean weighted $d=0.17, \mathrm{CI}=0.12,0.21$ ).

Effects shifted slightly when three anomalous studies were dropped (see Table 1, second column); then, the overall size of the priming effect was moderate (mean unweighted $d=0.49$, mean weighted $d=0.42, S D=0.42, S E=0.03,95 \% \mathrm{CI}=0.37,0.48$; $Z=15.13, p<.001) .{ }^{4}$ Though we assumed that effect sizes calculated excluding these studies were likely better estimates, the overall effect is not much influenced by including or excluding them in the database. To provide conservative estimates, we utilized all available studies in further analyses; we returned to the examination of effect sizes computed by including versus excluding anomalous studies as relevant.

\section{Moderator Analyses}

\section{Priming Task and Level of Collectivism Primed}

We first examined if the specific priming task or the level of collectivism primed in the task moderated the priming effect. We found significant differences in effect sizes between priming tasks (overall $Q_{\mathrm{B}}=47.48, p<.001$ ). The weakest results were found when language was used as the priming task. Effects were mod- erate in size and internally homogeneous for two of the most common priming tasks, the SDFF $(d=0.49)$ and the Sumerian warrior tasks ( $d=0.45$; both from Trafimow et al., 1991). As presented in detail in Table 3, first panel, other effects were either small or internally heterogeneous.

With regard to level of collectivism primed, the priming tasks that primed both relational- and group-level collectivism were the Sumerian warrior, subliminal prime, and scrambled sentence tasks. When these priming tasks were used, effects were larger $(d=0.52$, $\left.n=22 ; Q_{\mathrm{B}}=9.61, p<.01\right)$ than when only one level of collectivism was primed (group level: $d=0.28, n=11$; relational level: $d=0.39, n=28$; see Table 3 , second panel, for more detail).

\section{Dependent Variables and Their Operationalization}

With regard to dependent variables, the effect of priming was in the hypothesized direction and moderate in size for relationality $(d=0.61)$ and cognition $(d=0.54)$. The effect was in the hypothesized direction but small in size for values $(d=0.29)$ and self-concept $(d=0.26)$. For well-being, the evidence was less clear. The overall effect for well-being was negative and near zero

\footnotetext{
${ }^{4}$ The anomalous studies are the only study that assessed affect (Lee et al., 2000, Study 5) and two studies (Bond \& Yang, 1982; Yang \& Bond, 1980 ) that used language as a prime with a foreign experimenter to assess values in Hong Kong when it was still a British colony (so that English was likely associated with colonial power). The affect study did not provide information on a main effect of priming individualism and collectivism, focusing only on the interaction between priming individualism or collectivism and self-regulatory focus on promotion or prevention.
} 
Table 3

Effect of Priming as a Function of Prime (Task and Level of Collectivism Primed) and Dependent Variable (Category and Operationalization)

\begin{tabular}{|c|c|c|c|c|}
\hline Variable & $Q_{\mathrm{B}}$ & $d_{+}$ & $95 \% \mathrm{CI}$ & $Q_{\mathrm{wi}}$ \\
\hline \multicolumn{5}{|c|}{ Moderating effect of prime ${ }^{a}$} \\
\hline Priming task $(n)$ & $47.48^{* * *}$ & & & \\
\hline Pronoun circling (15) & & 0.34 & $0.23,0.46$ & $54.26^{* * *}$ \\
\hline SDFF (10) & & 0.49 & $0.31,0.67$ & 3.25 \\
\hline Sumerian warrior (12) & & 0.45 & $0.30,0.61$ & 13.34 \\
\hline Scrambled sentence (7) & & 0.32 & $0.14,0.51$ & 8.45 \\
\hline Group instantiation (3) & & 0.34 & $0.04,0.64$ & 2.98 \\
\hline Group imagination (8) & & 0.28 & $0.16,0.39$ & $63.55^{* * *}$ \\
\hline Language prime $^{\mathrm{b}}(10)$ & & 0.10 & $-0.02,0.21$ & $41.13^{* * * *}$ \\
\hline Unclassified prime (7) & & 0.78 & $0.60,0.96$ & $26.20^{* * *}$ \\
\hline Level of collectivism primed $(n)$ & $9.61^{* *}$ & & & \\
\hline Group (11) & & 0.28 & $0.18,0.39$ & $66.69^{* * *}$ \\
\hline Relational (28) & & 0.39 & $0.30,0.49$ & $60.14^{* * * *}$ \\
\hline Relational and group (22) & & 0.52 & $0.41,0.63$ & $59.32^{* * * *}$ \\
\hline \multicolumn{5}{|c|}{ Moderating effect of dependent variable } \\
\hline Outcome of interest $(n)$ & $66.30^{* * * *}$ & & & \\
\hline Relationality (13) & & 0.61 & $0.47,0.76$ & 18.16 \\
\hline Values (15) & & 0.29 & $0.19,0.40$ & $61.88^{* * * *}$ \\
\hline Self-concept (21) & & 0.26 & $0.17,0.34$ & $49.57^{* * * *}$ \\
\hline Well-being (4) & & -0.13 & $-0.30,0.05$ & $16.17^{* *}$ \\
\hline Cognition (28) & & 0.54 & $0.46,0.63$ & $88.87^{* * * *}$ \\
\hline \multicolumn{5}{|l|}{ Operationalization } \\
\hline Values $(n)$ & 1.79 & & & \\
\hline Individualism-collectivism (6) & & 0.40 & $0.21,0.59$ & 8.18 \\
\hline Other values (9) & & 0.25 & $0.12,0.37$ & $51.91^{* * * *}$ \\
\hline Self-concept measure $(n)$ & 0.97 & & & \\
\hline TST (24) & & 0.23 & $0.09,0.26$ & $38.73^{* *}$ \\
\hline Non-TST (19) & & 0.18 & $0.15,0.32$ & $131.87^{* * * *}$ \\
\hline Self-concept content (all studies) $(n)$ & $15.91^{* *}$ & & & \\
\hline Private self (18) & & 0.19 & $0.10,0.28$ & $41.08^{* * * *}$ \\
\hline Relational self (5) & & -0.03 & $-0.21,0.15$ & $59.44^{* * *}$ \\
\hline Collective self $(12)$ & & 0.36 & $0.25,0.47$ & $23.86^{*}$ \\
\hline Both relational and collective selves (8) & & 0.12 & $-0.02,0.27$ & $31.29^{* * * *}$ \\
\hline Self-concept content (TST studies) $(n)$ & $26.15^{* * *}$ & & & \\
\hline Private self (9) & & 0.31 & $0.17,0.44$ & $30.12^{* * * *}$ \\
\hline Relational self (3) & & -0.20 & $-0.41,0.01$ & $50.09^{* * *}$ \\
\hline Collective self $(8)$ & & 0.24 & $0.11,0.38$ & $15.36^{*}$ \\
\hline Both relational and collective selves (4) & & 0.67 & $0.38,0.95$ & $10.16^{*}$ \\
\hline Cognition $(n)$ & 0.91 & & & \\
\hline Social attitudes/judgments (10) & & 0.50 & $0.36,0.65$ & $20.41^{*}$ \\
\hline Social comparisons (10) & & 0.59 & $0.46,0.73$ & $64.71^{* * * *}$ \\
\hline Nonsocial judgments (8) & & 0.52 & $0.34,0.69$ & 2.84 \\
\hline
\end{tabular}

Note. $Q_{\mathrm{B}}=$ between-groups homogeneity coefficient; $d_{+}=$mean weighted effect size; CI $=$confidence interval; $Q_{\mathrm{wi}}=$ within-groups homogeneity coefficient; SDFF $=$ similarities and differences with family and friends task; TST $=$ Twenty Statements Task.

${ }^{a}$ When promotion focus and individualism cultural prime were matched, $d=0.42$ (95\% CI $=0.26,0.59 ; Q=16.96, p<.05$ ); when prevention focus and collectivism cultural prime were matched, $d=.51$ (95\% CI $=0.34,0.68 ; Q=12.10, p<.10)$.

${ }^{\mathrm{b}}$ Effect of language priming was $d=0.23(Z=3.42, p<.001 ; Q=24.74, p<.001)$, omitting Bond and Yang (1982) and Yang and Bond (1980), studies in which results may have been specific to English as a colonial language.

${ }^{*} p<.05 .{ }^{* *} p<.01 .{ }^{* * * *} p<.001$.

$(d=-0.13)$ but driven by a single study (Lee et al., 2000, Study $5 ; d=-0.39$ ) that we previously suggested excluding from the main effects analysis. Dropping this study increases the effect of priming on well-being from $d=-0.13$ to $d=0.32$, a small effect in the hypothesized direction (see Table 3, third panel, for more detail).

We explored the possibility that heterogeneous effects for outcomes were due to the interaction between the specific priming task used and outcome (asking whether certain tasks are more effective for certain outcomes). Effect sizes for the common primes are displayed in Figure 2. Table 4 details results; in the first panel, the most widely used tasks (pronoun circling, Sumerian warrior, SDFF, and scrambled sentence) are presented; in the second panel, effects of language as a priming task are presented Language is a relatively common prime, but as we have argued, what specifically is primed by language is less clear. In the third 


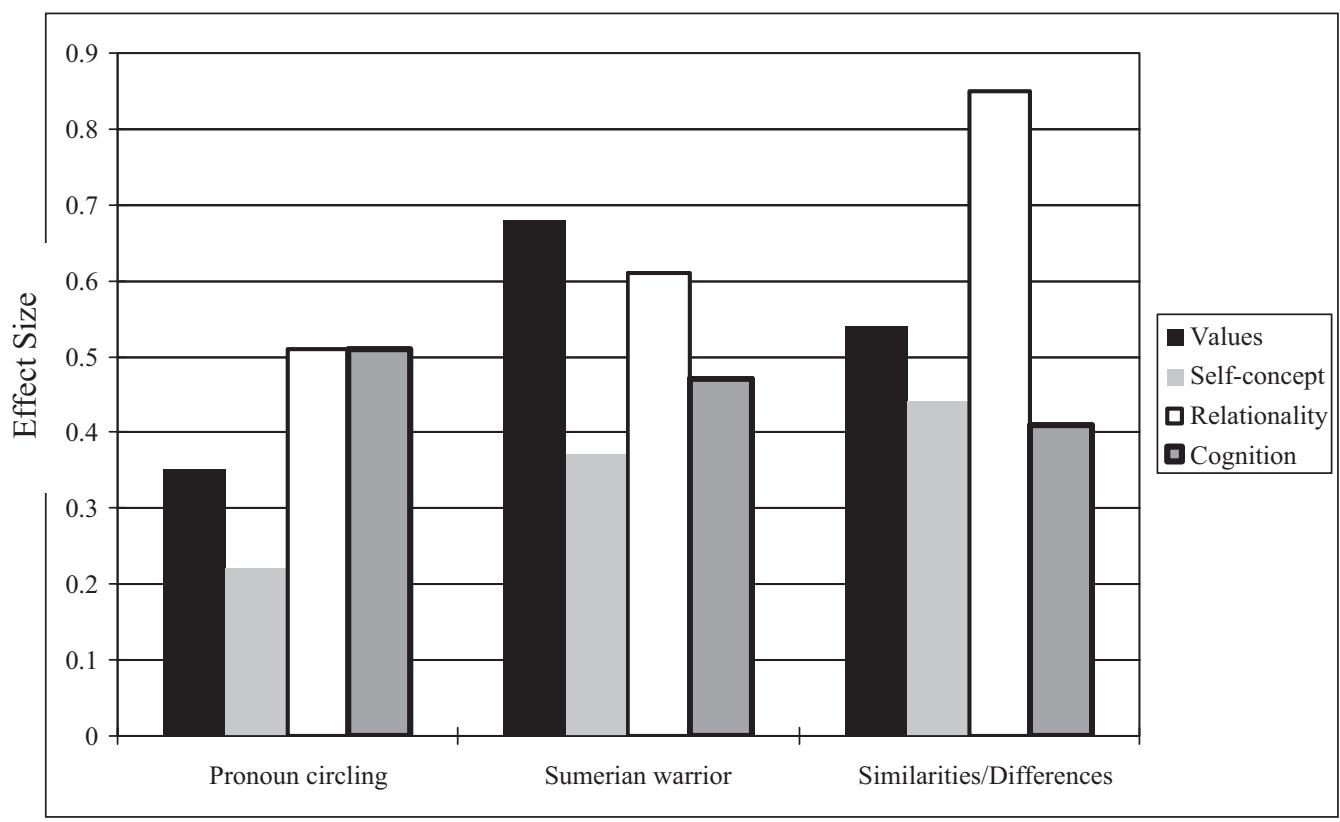

Figure 2. Efficacy of priming tasks across outcome domains.

panel, we present studies that used less common primes. These are primes used primarily or exclusively by single lab groups (group imagination, group instantiation). Primes not otherwise classified were included in this final group. As can be seen, the primes all produced effects. Effects were weaker for pronoun circling, potentially because of weaker effects when this task was used to study self-concept. Similarly, effects for the SDFF task were stronger potentially because of stronger effects when this task is used to study relationality.

We also conducted more detailed analyses based on the way dependent variables were operationalized. This more detailed analysis was unnecessary for relationality (because the average effect across studies showed no sign of heterogeneity) and impossible for well-being (because too few studies were found focused on this outcome). Below we outline the effect of operationalization for three outcomes: values, self-concept, and cognition.

Values. Values were either operationalized with standard individualism and collectivism value scales or with more ad hoc measures. As detailed in Table 3, fourth panel, this difference in operationalization mattered. The effect of priming on values was moderate and homogeneous ( $Q$ statistic not significant) when standard value scales were used. Small effect sizes and heterogeneity were found when other operationalizations were used. A few studies examined "Chineseness" (Bond \& Yang, 1982; Ross et al., 2002; Yang \& Bond, 1980). Other value outcomes were mostly based on single studies: equality proverbs (Briley \& Wyer, 2002, Study 3), justice values (Kemmelmeier et al., 2002, Study 3), and importance (Lee et al., 2000, Studies 2-4).

Table 4

Effect of Priming: Do Effects for Each Outcome Differ by Priming Task?

\begin{tabular}{|c|c|c|c|c|c|}
\hline \multirow[b]{2}{*}{ Prime } & \multicolumn{5}{|c|}{ Outcome $(n)$} \\
\hline & Values & Self-concept & Relationality & Cognition & Well-being \\
\hline \multicolumn{6}{|l|}{ Common priming tasks } \\
\hline Pronoun circling & $0.35(2)$ & $0.22(5)$ & $0.51(4)$ & $0.51(8)$ & - \\
\hline Sumerian warrior & $0.68(2)$ & $0.37(6)$ & $0.61(2)$ & $0.47(3)$ & $0.35(1)$ \\
\hline SDFF & $0.54(1)$ & $0.44(4)$ & $0.85(3)$ & $0.41(4)$ & - \\
\hline Scrambled sentence & $0.16(2)$ & - & $0.52(2)$ & $0.29(4)$ & - \\
\hline \multicolumn{6}{|c|}{ English as individualism prime } \\
\hline Language prime & $0.01(4)$ & $0.16(5)$ & $0.37(1)$ & $0.77(1)$ & $0.54(1)$ \\
\hline \multicolumn{6}{|c|}{ Less common priming tasks } \\
\hline Group imagination & $0.44(3)$ & $0.28(4)$ & - & $0.69(3)$ & $-0.39(1)$ \\
\hline Group instantiation & $0.23(2)$ & - & - & $0.27(2)$ & - \\
\hline Other/unclassified & - & $0.22(1)$ & $0.81(3)$ & $0.91(3)$ & $0.11(1)$ \\
\hline
\end{tabular}

Note. Each cell presents the mean weighted effect size and the number of studies from which the effect size was calculated in parentheses. A dash (-) was used when no studies fit a category. SDFF = similarities and differences with family and friends task. 
Table 5

Effect of Priming as a Function of Sample Characteristics

\begin{tabular}{|c|c|c|c|c|}
\hline Sample characteristic & $Q_{\mathrm{B}}$ & $d_{+}$ & $95 \% \mathrm{CI}$ & $Q_{\mathrm{wi}}$ \\
\hline Region $(n)$ & $24.90^{\text {**** }}$ & & & \\
\hline European American, European (50) & & 0.44 & $0.37,0.50$ & $178.25^{\text {**** }}$ \\
\hline Asian North American (3) & & 0.62 & $0.10,1.15$ & 3.42 \\
\hline Asian (22) & & 0.17 & $0.08,0.25$ & $59.96^{* * * *}$ \\
\hline Language conducted in $(n)$ & $44.10^{* * *}$ & & & \\
\hline English (44) & & 0.37 & $0.30,0.44$ & $118.90^{* * * *}$ \\
\hline German (9) & & 0.28 & $0.13,0.44$ & $23.24^{* *}$ \\
\hline Dutch (5) & & 1.00 & $0.80,1.20$ & $21.48^{* * * *}$ \\
\hline Chinese (1) & & -0.16 & $-0.59,0.28$ & - \\
\hline Gender $(n)$ & $4.18^{*}$ & & & \\
\hline Male (25) & & 0.10 & $-0.02,0.20$ & $65.68^{* * * *}$ \\
\hline Female (25) & & 0.27 & $0.15,0.38$ & $49.54^{* *}$ \\
\hline
\end{tabular}

Note. A dash (-) was used when no studies fit a category. $Q_{\mathrm{B}}=$ between-groups homogeneity coefficient; $d_{+}$ $=$ mean weighted effect size; $\mathrm{CI}=$ confidence interval; $Q_{\mathrm{wi}}=$ within-groups homogeneity coefficient.

${ }^{*} p<.05$. $_{* * *}<<.01 .{ }^{* * * *} p<.001$

Self-concept. Self-concept was operationalized either by content-coding a variant of the TST (Kuhn \& McPartland, 1954) or with other self-concept measures such as Singelis's (1994) or Leung and Kim's (1997) Self-Construal Scales, or self- versus group-focused thoughts (Aaker \& Lee, 2001, Study 1 pretest \& Study 2 pretest; Lee et al., 2000, Studies 2-4). Most studies used the TST, so we compared studies using the TST or other measures, in addition to comparing the effects of priming on content of self-concept both in general and in the TST studies only. In all three moderation analyses, the effect of priming on self-concept was small and heterogeneous across studies with one exception. The four TST studies that included both relational-level and grouplevel collective focus in a single category showed close-to-large effects on average $(d=0.67$; for details see Table 3 , fifth to seventh panels).

Cognition. We sorted cognition studies into three categories (social attitudes/judgments, social comparisons, and nonsocial judgments). As detailed in the bottom panel in Table 3, effect sizes were moderate and not significantly different $\left(Q_{\mathrm{B}}=0.91, p=.63\right)$ across operationalizations: social attitudes/judgments $(d=0.50$, $n=10)$, social comparisons $(d=0.59, n=10)$, and nonsocial judgments $(d=0.52, n=8){ }^{5}$ In the nonsocial judgment category we included studies focused on memory and visual perception.

\section{Sample Characteristics (Region, Language, and Gender)}

We examined the potential impact of sample characteristics (region, language, and gender of subjects) as carefully as possible. These analyses are necessarily limited by the fact that authors tended to focus on particular outcomes and stick with particular priming tasks so that region, language, task, and outcomes tended to cluster, limiting the efficacy of moderator analyses. With regard to language used, most studies $(n=44)$ were conducted in English in the U.S., Canada, and Hong Kong. The language used in the studies mattered $\left(Q_{\mathrm{B}}=44.10, p<.001\right.$; for details see Table 5, second panel). Although these results are potentially indicative of the moderating role of language, we cannot draw strong conclusions regarding the possibility that language itself may potentiate or undermine priming effects.
With regard to background and gender, when Asian participants were used or when gender was included in the analyses, studies were also more likely to use weak priming tasks or weak outcome operationalizations, contributing to smaller effects (for details, see Table 5, first and third panels). Effects for region and gender and the potential interplay between these and the prime (task and level of collectivism primed) or dependent variable (category and operationalization) were examined in detail, as generalization across study characteristics is critical if a conclusion is to be drawn about general, rather than country- or gender-specific, effects of priming individualism and collectivism (see Table 6). Most studies did not report gender, limiting gender analyses; however, results argued against assuming that gender plays an important role in sensitivity to individualism and collectivism priming (see Table 6 , gender columns).

Because region and language overlap, we focused on region in our moderator analyses (see Table 6, second column). These analyses suggest that "East-West" differences in priming effect may be importantly influenced by three factors related to tasks used. First, different priming tasks were used in the East and the West; second, whereas in the West various levels of collectivism were primed, in the East most studies used group-level collectivism primes $(60 \%$ of studies, which produced small effects for Asian samples). Third, studies conducted in the East relied heavily on language as a priming task (40\% of studies), yet the overall effect of using language as a prime was near $d=0.00$.

\footnotetext{
${ }^{5}$ Although eight studies examined the effects of matching selfregulatory focus with priming, none reported an effect of culture priming on self-regulatory focus. Rather, four of these studies focused on the effects of matching self-regulatory focus and culture prime on salient values (Briley \& Wyer, 2002, Study 3; Lee, Aaker, \& Gardner, 2000, Studies 2-4), and four of these studies focused on the effects of matching selfregulatory focus and culture prime on other cognitive process variables such as memory (Aaker \& Lee, 2001, Studies 1-4). Across outcome domains, matching cultural prime and self-regulatory focus had a moderate average effect size (promotion and individualism, $d=0.42$; prevention and collectivism, $d=0.51$; both $p$ s $<.001$ ).
} 
Table 6

Size of Effect by Sample Characteristics: Moderating Effect of Prime (Task, Level of Collectivism Primed) and Outcome (Category, Operationalization)

\begin{tabular}{|c|c|c|c|c|c|}
\hline \multirow[b]{2}{*}{ Variable } & \multicolumn{2}{|c|}{ Gender } & \multicolumn{3}{|c|}{ Region } \\
\hline & Male $(n)$ & Female $(n)$ & $\begin{array}{l}\text { European American } \\
\text { or European }(n)\end{array}$ & $\begin{array}{c}\text { Asian } \\
\text { American }(n)\end{array}$ & Asian $(n)$ \\
\hline \multicolumn{6}{|c|}{ Moderating effect of prime } \\
\hline \multicolumn{6}{|l|}{ Priming task } \\
\hline Pronoun circling & $0.69(3)$ & $0.60(3)$ & $0.33(15)$ & $1.38(1)$ & - \\
\hline Sumerian warrior & $0.45(3)$ & $0.67(3)$ & $0.47(10)$ & - & $0.44(2)$ \\
\hline SDFF & $0.55(6)$ & $0.59(7)$ & $0.51(9)$ & $0.32(1)$ & $0.38(1)$ \\
\hline Scrambled sentence & $0.79(2)$ & $0.75(2)$ & $0.31(5)$ & - & $0.34(3)$ \\
\hline Language prime & $-0.14(7)$ & $0.05(6)$ & - & - & $0.07(9)$ \\
\hline Group imagination & $0.04(4)$ & $0.05(4)$ & $0.35(7)$ & - & $0.18(6)$ \\
\hline Group instantiation & - & - & - & - & $0.34(3)$ \\
\hline Other/unclassified & - & - & $0.81(7)$ & $0.28(1)$ & - \\
\hline \multicolumn{6}{|l|}{ Level of collectivism primed } \\
\hline Relational self & $0.59(9)$ & $0.59(10)$ & $0.39(27)$ & $0.84(2)$ & $0.38(1)$ \\
\hline Collective self & $0.04(4)$ & $0.05(4)$ & $0.35(7)$ & - & $0.22(9)$ \\
\hline Both relational and collective selves & $0.54(5)$ & $0.70(5)$ & $0.57(18)$ & $0.28(1)$ & $0.38(5)$ \\
\hline \multicolumn{6}{|c|}{ Moderating effect of dependent variable } \\
\hline \multicolumn{6}{|l|}{ Outcome of interest } \\
\hline Values & $0.19(7)$ & $0.34(6)$ & $0.50(8)$ & $0.66(1)$ & $0.15(11)$ \\
\hline Self-concept & $0.14(9)$ & $0.24(10)$ & $0.31(15)$ & $1.14(2)$ & $0.16(8)$ \\
\hline Relationality & $0.80(4)$ & $0.82(5)$ & $0.64(12)$ & $1.21(1)$ & - \\
\hline Cognition & $0.73(8)$ & $0.51(8)$ & $0.57(23)$ & $0.51(1)$ & $0.44(7)$ \\
\hline Well-being & $-0.31(3)$ & $0.02(3)$ & $-0.26(3)$ & $0.06(1)$ & $0.01(2)$ \\
\hline \multicolumn{6}{|l|}{ Operationalization } \\
\hline \multicolumn{6}{|l|}{ Values } \\
\hline Individualism-collectivism & - & - & $0.39(4)$ & $0.66(1)$ & $0.39(4)$ \\
\hline Other values & $0.19(7)$ & $0.34(6)$ & $0.56(4)$ & - & $0.08(7)$ \\
\hline \multicolumn{6}{|l|}{ Self-concept (all studies) } \\
\hline Private self & $-0.02(7)$ & $0.14(8)$ & $0.16(12)$ & $1.16(2)$ & $0.17(8)$ \\
\hline Relational self & $-0.23(4)$ & $0.08(4)$ & $0.43(2)$ & - & $-0.20(3)$ \\
\hline Collective self & $0.34(7)$ & $0.30(7)$ & $0.62(7)$ & $0.42(1)$ & $0.23(7)$ \\
\hline Mixed relational and collective selves & $0.00(2)$ & $0.08(3)$ & $0.11(6)$ & $1.89(1)$ & $0.00(2)$ \\
\hline \multicolumn{6}{|l|}{ Cognition } \\
\hline Social attitudes/judgments & $1.86(1)$ & $0.01(1)$ & $0.58(6)$ & - & $0.40(5)$ \\
\hline Social comparisons & $0.69(1)$ & $0.65(1)$ & $0.60(10)$ & $0.51(1)$ & - \\
\hline Nonsocial judgments & $0.55(6)$ & $0.57(6)$ & $0.51(7)$ & - & $0.54(2)$ \\
\hline
\end{tabular}

Note. The number of studies used to calculate effects is presented in parentheses. When no studies were found in a category, this is denoted using a dash $(-)$ SDFF $=$ similarities and differences with family and friends task.

Four tasks (Sumerian warrior, SDFF, scrambled sentence, and group imagination) were used in both Eastern and Western studies. The pronoun circling task, common in Western samples, has not been attempted with Asian samples; the group instantiation prime has not been attempted with Western samples. The unclassified primes, ambiguous as to content, had high overall effects and have not been used in Asian samples. When language as priming task was removed from analyses and the effect of "unclassified" primes was ignored (as these do not form an identifiable group), effect sizes were similar across regions. Effects were small for Asians $(d=0.27, n=14)$, European Americans/Europeans $(d=0.38$, $n=34)$, and Native Americans $(d=0.32, n=1)$ and larger for Asian Americans $(d=0.84, n=2)$, suggesting comparable sensitivity to individualism and collectivism priming. Direct comparison of effects in studies using the same priming tasks suggests that effects were moderate for the Sumerian warrior (European
Americans/Europeans, $d=0.47$; Asians, $d=0.44$ ) and SDFF tasks (European Americans/Europeans, $d=0.51$; Asians, $d=$ 0.38 ), and small for the scrambled sentence task (European Americans/Europeans, $d=0.31$; Asians, $d=0.34$ ). Asians seemed less amenable to the group imagination task (European Americans/ Europeans, $d=0.35$; Asians, $d=0.18$ ). This task involves imagining oneself playing tennis alone or on a team and may not capture collectivism well in an Asian context. Taken together, it seems that aspects of individualism and collectivism can be primed in the East and the West when using the Sumerian warrior and the SDFF tasks. It is not yet known if the pronoun circling task is effective in the East; effects for scrambled sentence tasks were small.

We also examined the possibility of regional differences in the outcomes sensitive to priming effects. None of the studies using Asian participants examined effects on relationality, and there 
were insufficient studies focused on well-being to make any comparison. Difficult to interpret regional differences were found for the salient content of working self-concept. Various analytic attempts to tease out the source of seemingly smaller priming effects on the content of working self-concept in Asian compared with Western participants failed to clarify the picture. We first examined whether smaller effects are due to the use of language as a prime. Although half of the Asian region self-concept studies used language as a prime, effects for Asian participants $(d=0.17, n=$ 4) did not much increase when these studies were dropped; similarly, effects for Asians were stable when only self-concept studies using the TST were used ( $d=0.16, n=4)$. Effects for Westerners were larger when any collective content (whether group or relational level) was coded together. It is possible that the content of the working self-concept is less amenable to priming for Asian participants; it is also possible that the coding is error-prone or Western-biased.

Finally, focusing on outcomes with internally homogeneous priming effects (presented graphically in Figure 3), results were moderate and comparable when standard values scales were used (European Americans/Europeans, $d=0.39$; Asians, $d=0.39$ ) and for cognition as assessed in social and nonsocial judgments. Examining the subgroup of studies where more direct comparison is possible, we found no difference by region and a moderate sized effect of priming (European Americans/Europeans: $d=0.56, n=$ 26; Asian Americans: $d=0.58, n=2$; Asians: $d=0.43, n=10$; $\left.Q_{\mathrm{B}}=n s\right)$.

\section{Summary and Implications of Moderator Analyses}

We conducted an extensive review of the individualism and collectivism priming literature, finding that a consistent picture emerges even though primes are diverse in content, in the type of task used, and in their transparency to the participant. This diversity is helpful: If meta-analytic results from priming studies are consistent across different types of primes and when different levels of collectivism are primed, this constitutes strong evidence that the underlying process of collectivism is the same across different levels of groups (relational vs. collective), an issue unresolved by the cross-cultural, cross-national comparative literature. Similarly, if effects of priming are the same for participants whether they are male or female, and no matter which society they come from, a strong case can be made that individualism and collectivism have effects that are discernable even if they naturally co-occur with other factors or occur with different likelihoods in different societies. Indeed, individualism and collectivism priming tasks evoke congruent responses that fit the direction postulated by cross-cultural research.

For the most part, effects were heterogeneous, moderated by the priming task used, the level of collectivism primed in the task, the outcomes studied, and how these outcomes were operationalized. Because understanding sources of heterogeneity is an important first step toward a better understanding of the active ingredients of individualism or collectivism cued in real-world settings of everyday life, we examined method-related heterogeneity in some detail and then turned to heterogeneity by outcomes.

Language as a prime. One priming task that produced widely varying results was the use of language as a prime. As noted consistently across reviews focused on a variety of languages (e.g., Chiu, Leung, \& Kwan, 2007; Liu, 1986; Norenzayan, Choi, \& Peng, 2007; Wang \& Ross, 2007), language is related to culture, memory, and cognition. Studies using language are limited to participants who are bilingual or multilingual. However, the potential effects of language can be operationalized and studied with other primes, thus disentangling language from other culturerelevant factors. Our interpretation of the available data to date is that the meaning of language is highly contextualized and influenced both by the meaning given to the request to use one language or another and by its interface with the nature of the task.

This latter interpretation comes from a research tradition focusing on language as a tool for thinking (Semin, 2000). Work within this paradigm highlights both differences in language use depending on the nature of dependency with the other (de Montes, Semin, \& Valencia, 2003) and also differences in the structure of language, particularly the use of concrete compared to abstract lan-

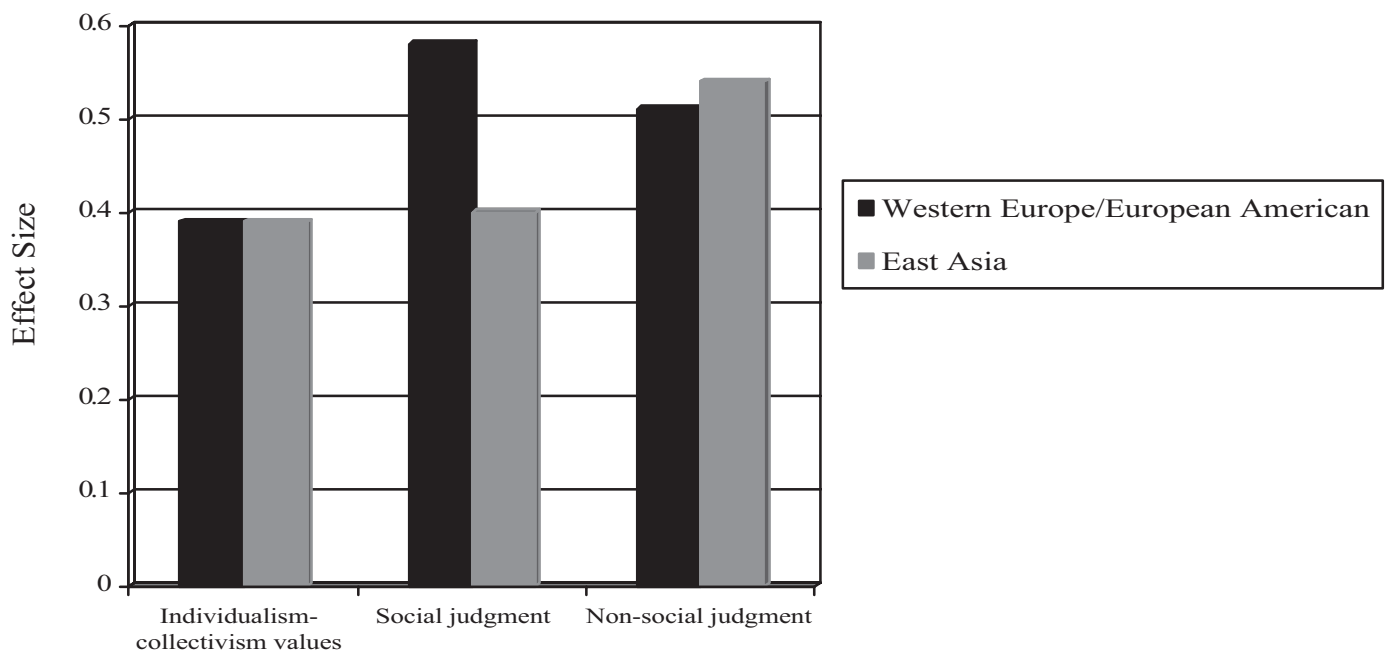

Figure 3. Size of priming effects in Eastern and Western countries. 
guage (operationalized as verbs compared to adjectives) in describing life events as well as other people (e.g., Stapel \& Semin, 2007). Semin, Görts, Nandram, and Semin-Goossens (2002) and Maass, Karasawa, Politi, and Suga (2006) provided evidence of cross-national differences. For example, Maass et al. found that Italians favored abstract language (context-free adjectives as descriptors) and Japanese favored concrete language (contextlimiting verbs as descriptors). These studies imply that language does not simply cue individualism or collectivism; it also likely cues ways of thinking (e.g., concrete and detail-focused or abstract).

Other primes. Unlike the heterogeneity we found in tasks using language as a prime, the SDFF and the Sumerian warrior tasks had more consistent and robust effects on salient processing style and content (values, content of self-concept, and ways of relating to and engaging others). Here too we found some variability, particularly for different operationalizations of values and self-concept, with larger effects for more standard operationalizations of values.

Effects of priming on outcomes. The effect of individualism and collectivism priming on values was most notable in studies using the SDFF task, the Sumerian warrior story, and one of the group imagination tasks; the effect was smaller when the pronoun circling task, scrambled sentence task, and language as culture prime task were used. It is possible that the former tasks are particularly successful in cuing values because they all explicitly focus on commonality with group members. The latter tasks are explicitly language-based and focus on the structure of language. This more subtle approach means that participants are less likely to be aware of what is cued, but it also means that congruent values may not necessarily come to mind. In addition, the group instantiation tasks showed weak effects on values. Group instantiation tasks are minimal group paradigms, so the created groups were likely not powerful enough to strongly cue values attached to individualism or collectivism.

Perhaps for the same reason, the SDFF and Sumerian warrior tasks were most effective at shifting content of self-concept; although effects for these tasks were in the moderate to small range, effects were quite small when the less direct primes were used. When content of self-concept was the focus of analysis, effects were heterogeneous and were influenced among other things by the priming task used. Data from more regions as well as from gender-level analyses are needed to disentangle effects. However, heterogeneity may be inherent in the self-concept measurement tool, and it is difficult to obtain a stable measure of content of working self-concept from content coding of the limited text responses of participants.

The final set of outcomes focused on cognitive style. The effects of priming on cognitive style were in the moderate to high range for all of the priming tasks except the scrambled sentence and group instantiation tasks. Weak effects for group instantiation tasks may be due to the minimal group character of the studies. That priming aspects of individualism and collectivism produced shifts in stated value content and in feelings of closeness to in-group others in the direction expected by cross-national models of culture suggests that the priming studies are providing an analogue of the differences found cross-culturally. That priming individualism and collectivism produced shifts in cognitive procedures (e.g., improving ability to remember where unrelated objects were located on a page after collectivism priming; Kühnen \& Oyserman, 2002) suggests that individualism and collectivism influence both the what and the how of thinking.

Taken as a whole, results suggest that individualism and collectivism can be primed by a variety of priming tasks. Individualism and collectivism, when accessible and salient, produced effects on values, self-concept, relationality, and cognitive processes as predicted in the cross-national literature. By making individualism or collectivism salient, these studies demonstrate that judgment and behavior are cued by these cultural factors. A missing piece in our discussion so far is the question of whether priming tasks are equally effective in shifting toward collectivism and toward individualism. This cannot be ascertained without a comparison to control. The next set of analyses focuses on the subset of studies that provided this information.

\section{Comparison to Control}

Priming either individualism $(d=0.35,95 \% \mathrm{CI}=0.23,0.48)$ or collectivism ( $d=0.34,95 \% \mathrm{CI}=0.21,0.46)$ significantly shifted responses compared to control, and effect size did not differ by individualism versus collectivism prime $\left(Q_{\mathrm{B}}=0.04, p=.85\right)$. Although no different in their average effect compared to control, studies differ in that the effects of priming individualism were homogeneous $(Q=11.30, p=.59)$, whereas the effects of priming collectivism were not $(Q=30.56, p<.01)$.

More detailed analyses are presented in Table 7, which shows that effects were comparable for priming individualism and collectivism, with collectivism more powerfully primed by tasks that cue both relational-level and group-level collectivism (first and second panels). Priming individualism produced significant effects ( $d$ s from 0.27 to 0.39 ; third panel). Priming collectivism also had significant effects, but effects were more heterogeneous, ranging from very small (relationality, $d=0.06$; self-concept, $d=0.14$ ) to moderate (values, $d=0.41$; cognition, $d=0.52$ ). We could take a more detailed look by examining possible operationalization effects for two outcome categories (self-concept and cognition) Taking a more detailed look did not shed light on the smaller effect of collectivism primes on self-concept (fourth and fifth panels). With regard to cognition, comparisons could be made for effects of priming on social comparisons. In this case, effects appear stronger for priming collectivism than for priming individualism. Effects for priming nonsocial judgments are less interpretable because there were only two studies for each comparison. Finally, with regard to sample characteristics (bottom two panels), we did not find gender differences. ${ }^{6}$ Only three studies included Asian participants, and on the basis of this limited evidence, it may be that Asian participants are less sensitive to collectivism priming. Taken together, the studies that included comparison to control suggest that both individualism and collectivism can be primed, that the impact on the content of self-concept, relationality, and values has been better documented for individualism than collectivism, but

\footnotetext{
${ }^{6}$ For men, individualism prime-control condition versus collectivism prime-control condition, $Q_{\mathrm{B}}=0.72, p=.39$. For women, individualism prime-control condition versus collectivism prime-control condition, $Q_{\mathrm{B}}=0.09, p=.77$. For individualism prime-control condition, men versus women, $Q_{\mathrm{B}}=0.23, p=.63$. For collectivism prime-control condition, men versus women, $Q_{\mathrm{B}}=0.05, p=.82$.
} 
Table 7

Effect of Priming Compared to Control: Moderating Effects of Prime (Task, Level of Collectivism Primed), Outcome (Category, Operationalization), and Sample Characteristics

\begin{tabular}{|c|c|c|}
\hline \multirow[b]{2}{*}{ Variable } & \multicolumn{2}{|c|}{ Comparison } \\
\hline & $\begin{array}{l}\text { Individualism } \\
\text { vs. control }(n)\end{array}$ & $\begin{array}{c}\text { Collectivism } \\
\text { vs. control }(n)\end{array}$ \\
\hline \multicolumn{3}{|c|}{ Moderating effect of prime } \\
\hline \multicolumn{3}{|l|}{ Priming task } \\
\hline Pronoun circling & $0.44(5)$ & $0.30(5)$ \\
\hline Sumerian warrior & $0.30(3)$ & $0.22(3)$ \\
\hline SDFF & $0.42(3)$ & $0.13(3)$ \\
\hline Scrambled sentence & $0.08(3)$ & $0.55(3)$ \\
\hline Unclassified & $0.35(1)$ & $1.08(1)$ \\
\hline \multicolumn{3}{|l|}{ Level of collectivism primed } \\
\hline Relational & $0.43(8)$ & $0.23(8)$ \\
\hline Mixed relational and collective group & $0.25(7)$ & $0.48(7)$ \\
\hline Collective group & - & - \\
\hline \multicolumn{3}{|c|}{ Moderating effect of dependent variable } \\
\hline \multicolumn{3}{|l|}{ Outcome of interest } \\
\hline Values & $0.27(2)$ & $0.41(2)$ \\
\hline Relationality & $0.37(4)$ & $0.14(4)$ \\
\hline Self-concept & $0.35(3)$ & $0.06(3)$ \\
\hline Cognition & $0.39(6)$ & $0.52(6)$ \\
\hline \multicolumn{3}{|l|}{ Operationalization } \\
\hline \multicolumn{3}{|l|}{ Self-concept } \\
\hline Private self & $0.30(2)$ & $0.03(2)$ \\
\hline Relational self & $0.45(1)$ & $0.08(1)$ \\
\hline Collective self & $0.30(2)$ & $0.06(2)$ \\
\hline \multicolumn{3}{|l|}{ Cognition } \\
\hline Social attitudes/judgments & - & - \\
\hline Social comparisons & $0.33(4)$ & $0.73(4)$ \\
\hline Nonsocial judgments & $0.54(2)$ & $0.03(2)$ \\
\hline \multicolumn{3}{|c|}{ Moderating effect of sample characteristic } \\
\hline \multicolumn{3}{|l|}{ Gender } \\
\hline Male & $0.45(6)$ & $0.23(6)$ \\
\hline Female & $0.34(6)$ & $0.29(6)$ \\
\hline \multicolumn{3}{|l|}{ Region } \\
\hline European American/European & $0.36(11)$ & $0.44(11)$ \\
\hline Asian & $0.34(3)$ & $0.08(3)$ \\
\hline
\end{tabular}

Note. The number of studies on which an effect size is based is presented in parentheses; if no studies were found for a category then we used a dash (一) to note this. SDFF $=$ similarities and differences with family and friends task.

that the impact on cognitive processes is close to moderate in size whether individualism or collectivism has been primed. Priming effect was consistent across East and West for individualism. Effects for collectivism were less clear, potentially due to the weak tasks used.

\section{Robustness of Results in Studies Priming Either Individualism or Collectivism}

A final set of analyses, which we conducted on the studies summarized in supplemental Appendix B, Tables B1-B4, supports the robustness of our findings, adds to the countries on which conclusions can be based, and provides some particularly compel- ling examples of behavioral effects. Recall that Appendix B includes 11 studies with ambiguities in priming tasks (only 6 of which provided data that could be used to calculate effect sizes) and 21 studies that used either individualism or collectivism primes but not both. First, taken as a whole, the effect size (mean unweighted $d=0.47$, mean weighted $d=0.39, S D=0.35, S E=$ $0.05,95 \% \mathrm{CI}=0.30,0.48)$ is comparable to the effects in the main meta-analysis (mean unweighted $d=0.45$, mean weighted $d=$ $0.34, S D=0.34, S E=0.02,95 \% \mathrm{CI}=0.29,0.39)$. Both are significantly different from a null effect (main analysis $Z=12.90$, $p<.001$; Appendix B analyses, $Z=8.63, p<.001$ ). As before, effect sizes ranged from small (values and self-concept) to moderate (relationality and cognition). However, the difference in effect sizes in this case was not significant $\left(Q_{B}=1.84, p=.61\right)$. Of these studies, only two focused on values (Bovasso, 1997; Briley \& Wyer, 2001, Study 3). The latter study is important because, though the prime itself is unclear, it shows effects of priming on values for both American and Hong Kong participants. Because some of the studies that primed only individualism or collectivism and examined their effects on self-concept, relationality, and cognition attempted to disentangle active ingredients within each construct or included innovative results that add to the main meta-analytic findings, we discuss these studies in some more detail.

\section{Relationality}

In addition to one study with a difficult-to-interpret prime (Mandel, 2003, Study 2), thirteen studies examined the effect of priming either individualism $(n=6)$ or collectivism $(n=7)$ on relationality $(d=0.41)$; effects are similar in size to those found in the main meta-analysis. Moreover, these studies provide interesting hints as to the process by which individualism and collectivism cue behavior. U.S. undergraduates felt closer to others after using "we" to describe a relationship rather than after describing the self and the other separately ("my friend and I"; Fitzsimons \& Kay, 2004, Studies 1-4). Dutch participants primed with first person pronouns (I) compared to third person pronouns (he) exhibited less automatic mimicry (van Baaren et al., 2003, Study 1), presumably because the $I$-priming cued difference and separateness rather than closeness with others. Dutch participants primed with their own name rather than a neutral word sat closer to a confederate (Holland et al., 2004, Study 1). This effect suggests that other persons can be imbued with value by being linked to the self.

\section{Self-Concept}

In addition to three studies with difficult to interpret primes and findings (Chen et al., 2004, Study 2; Gaertner et al., 1999, Study 3; Kanagawa et al., 2001), studies that primed only collectivism or individualism showed effects of similar size $(d=0.35)$ as those in the main meta-analysis. Two studies examined microprocesses within individualism priming tasks. Using a subliminal priming procedure to prime $I$ or a neutral word, Mussweiler and Bodenhausen (2002, Study 3) showed that I-primed U.S. male participants were faster at recognizing female trait words as not selfdescriptive compared with male participants primed with a neutral word. This complicates typical contrasts between individualistic and collectivistic foci of self-concept content, because these results 
suggest that the content of the individual self includes information about social category membership.

Stapel and Koomen (2001, Study 4) decomposed individualism priming effects and showed that using the pronoun circling task cues self-enhancement among Dutch participants but that priming individualism does not necessarily do so. When they used a scrambled sentence task to cue separation and distinction separately from self-enhancement, they showed that priming the "distinct" and "separate" aspects of individualism does cue selfenhancement. Because self-enhancement has been described as part of a Western syndrome of individualism (Markus \& Kitayama, 1991), future research using Stapel and Koomen's and Mussweiler and Bodenhausen's (2002) priming tasks with Eastern participants is needed to discover whether priming with first person pronouns cues both self-enhancement and social category membership equally across societies.

\section{Cognition}

In addition to one study with a difficult-to-interpret prime (Briley \& Wyer, 2002, Study 6), four studies examined the effect of priming either individualism $(n=1)$ or collectivism $(n=3)$ on cognition $(d=0.50)$; effects are similar in size to the main meta-analysis effects. Of note is Brewer and Gardner (1996, Studies 1-2), who showed equal effects of we-priming whether the "we" primed is relational (e.g., friends going to the city) or a large group (e.g., everyone sitting in a sports stadium), suggesting congruence at least for American participants in the effects of relational- and group-level collectivism.

\section{Summary of Single-Prime Studies}

Across relationality, self-concept, and cognition, the estimated size of the effect of priming individualism and collectivism was comparable whether both individualism and collectivism were primed (between subjects, as in the main set of analyses) or only one of these primes was used. These studies both lend support to the robustness of priming effects revealed by the main metaanalysis and also add some needed breadth to the methods and outcomes of priming. With regard to region of the world included, although participants from the U.S., Germany, the Netherlands, and Hong Kong were again represented, these studies also included participants from Canada, the United Kingdom, and Japan. In this group of studies there were also some insights into the processes that may underlie individualism and collectivism. A few studies begin to unpack the effects of priming individualism, separating out the effects of priming difference from the effects of priming positive uniqueness as well as demonstrating that priming the self also primes salient social identities, even among Americans. These results are important because they go beyond what can be tested with straightforward cross-national comparisons and provide a mechanism for testing cultural factors such as individualism and collectivism. To fulfill their promise, results from these microprocesses would need to be replicated in societies other than those typically identified with individualism.

\section{Integration of Meta-Analytic Results with Other Evidence}

Oyserman, Coon, and Kemmelmeier's (2002) meta-analyses of cross-national comparisons between European Americans and oth- ers suggest a moderate-sized difference in endorsement of individualism and collectivism values, with some caveats. Because cross-national comparisons are correlational, they cannot provide access to process, leaving open the question of whether individuals from different societies always differ in individualism and collectivism values or if the salience of these values depends on what comes to mind in the moment.

Our review of the priming literature provides evidence supporting the association between individualism and collectivism and values, ways of engaging others, content of self-concept, and cognition found in the cross-national literature. Across studies using control groups, shifts in judgment and behavior due to (primed) individualism are demonstrated, whether the region studied is the U.S. or Europe $(d=0.36)$ or Asia $(d=0.34)$. With regard to collectivism, the size of the shift in judgment behavior due to (primed) collectivism $(d=0.44)$ is comparable for samples drawn from the U.S. and Europe. Research from Asia does not show effects of (primed) collectivism of this order $(d=0.08)$; as we noted in the results section, part of the problem seems to be reliance on weaker primes and potential confounds between language and priming task in these studies. Even given these caveats, the current meta-analytic results strengthen the causal argument that cultural factors influence psychological outcomes. As we discuss below, some of the posited effects of individualism and collectivism are more strongly supported than others, and future research is still needed to tease apart the extent to which culture's influences are strongly felt via individualism and collectivism compared to other potentially important cultural factors such as honor or power distance.

Across individualism and collectivism priming tasks, effects are moderate in size $(d=0.40)$ when the kinds of value scales used in the cross-national literature are employed; compared to control, (primed) collectivism $(d=0.42)$ influences values, as does (primed) individualism $(d=0.27)$. When cued with individualism, participants endorse individualistic values more, compared to when cued with collectivism. Although the evidence comes mostly from European American and Western European participants, studies with Asian, primarily Hong Kong Chinese, participants show parallel effects. Priming individualism and collectivism shifts salience of individualism- and collectivism-relevant values with about the same magnitude of effect as is found in the crossnational literature. Size of effect is comparable for European Americans $(d=0.39)$ and Asians $(d=0.39)$ and is influenced by the kind of prime used, with effects in the $d=0.54$ to 0.68 range found when the Sumerian warrior and SDFF primes are used. When compared to a no-prime control, effects were found when either individualism or collectivism was primed.

With regard to relationality, across individualism and collectivism priming tasks, effects are moderate to large in size $(d=0.61)$ when the effect of individualism and collectivism on ways of engaging others is assessed. Compared to control, (primed) individualism $(d=0.37)$ influences relationality, as does (primed) collectivism $(d=0.14)$. Unfortunately, the priming literature on relationality is limited to Western samples. We found only one study that assessed the effects of priming on relationality using an Asian American sample (Gardner et al., 2004), suggesting a need for further research in other regions of the world.

With regard to self-concept, effects of individualism and collectivism are heterogeneous in the cross-national literature, and 
this is also true for the studies using priming tasks to isolate effects of individualism and collectivism from other potential effects. Both literatures heavily rely on content coding of responses to the TST to obtain information about content of self-concept. Effects are dependent on which aspect of self-concept is the focus of analyses, with larger effects when the salience of relational and collective selves are coded together $(d=0.67)$ and small effects otherwise ( $d=0.23$ for all TST results combined, and $d=0.18$ for all non-TST results combined). Across operationalizations of selfconcept, when primed and nonprimed control groups are compared, effects on self-concept are larger when individualism $(d=$ $0.35)$ is primed than when collectivism is primed $(d=0.06)$, suggesting that individualism functions to dampen social content in self-concept more than collectivism promotes it. When collective self-descriptors are the focus of analyses, effects are consistent across gender but smaller for Asian than for Western samples.

Finally, with regard to cognitive style, effects are in the high moderate range ( $d=0.52$ to 0.59 ) across very different operationalizations of cognitive style and across priming tasks. Moreover, in studies that use comparison to control, the effects of priming individualism $(d=0.39)$ and collectivism $(d=0.52)$ are comparable, suggesting that both cultural frames influence cognitive style. With regard to region, effects are comparable in Asia $(d=$ $0.44)$ and the U.S. or Europe $(d=0.52)$. Effect size parallels the cross-national research and lends support to the notion that individualism and collectivism influence cognitive style, even though they cannot parse the relative size of the effect of individualism and collectivism compared with effects of other potentially relevant variables. Taken together, results suggest that collectivism increases the likelihood of including rather than excluding information, assimilating and relating rather than contrasting and separating information. Similarly, individualism increases the likelihood of using contrasting procedures, pulling apart and separating rather than integrating and connecting. Thus, priming collectivism versus individualism shifts speed of recognition of embedded figures and letters made up of other letters (Kühnen \& Oyserman, 2002) and speed in the Stroop test (Oyserman et al., 2008). These effects parallel cross-national effects found by Norenzayan et al. (2007), Nisbett (2003), and Kitayama (e.g., Kitayama, Duffy, Kawamura, \& Larsen, 2003).

\section{Conclusion}

The cross-national literature on the effects of individualism and collectivism is both impressive and spotty. It is impressive because across outcomes, operationalization of outcome measures, and samples, results converge in demonstrating differences in values as predicted by individualism and collectivism as well as evidence that these differences have psychological consequences for individuals. Cross-national studies also show differences in how the self is defined, how relationships with others are imagined, what is of value, and how the mind works consistent with effects posited within an individualism and collectivism framework. These results are important because cross-national comparisons have ecological validity; after all, they demonstrate real differences between real groups. Because these differences are patterned and seem consistent with hypothesized effects of individualism and collectivism, it is tempting to assume that they are due to individualism and collectivism. However, cross-national comparisons cannot of themselves provide conclusive support of this causal role, and for this reason the cross-national evidence can be considered spotty.

Take for example, the results of two cross-national studies examining the impact of culture on cognition. Jensen and Whang (1994) tested Los Angeles schoolchildren in fourth to sixth grade, finding that Chinese children outperformed European American children by a third of a standard deviation on the Raven's Progressive Matrices test, a task that requires pattern matching and noticing missing elements in visual displays. Kitayama et al. (2003) showed differential accuracy of American and Japanese respondents to line-drawing tasks requiring recall of lines either in relation to a provided background (tasks that Japanese respondents are better at) or separate from this background (tasks that American respondents are better at). Taken together, both sets of studies strongly imply an effect of culture on cognition. But they cannot address the question of which aspects of culture matter, and they are mute as to whether the active ingredients of culture that are studied are specific to a particular society (e.g., China, Japan) or generalizable across a class of societies (e.g., those high in collectivism or those low in individualism).

The literature reviewed in this article provides a next step in addressing these issues. This literature utilizes the logic of experimentation to move beyond ecologically valid but causally ambiguous cross-national studies to study some specific operationalizations of active ingredients of culture, focusing on individualism and collectivism. Across studies, the question asked is if the proposed association between culture and cognitive processes, for example, is stronger when an aspect of individualism or collectivism is made accessible and salient.

These studies build on assumptions made in cross-national comparative research that provide information about average cross-national differences. By contrasting effects between groups or countries assumed to differ in individualism and collectivism, this methodology implies that contrasting results are due to contrasting influences of individualism and collectivism. But to make the leap from cross-national observed differences in judgment and behavior to the assertion that effects are due to individualism and collectivism requires assuming an average chronic tendency for either individualism or collectivism to be salient and accessible and thus available to influence judgment and behavior. This implied contrast is made explicit in the current main analyses. The priming technique facilitates testing cultural factors by clarifying what is salient and accessible to the participant at the point that judgment is made or behavior engaged in. By randomizing participants to condition, effects cannot be attributed to difference at the individual level or to personality factors. By including a comparison to control, researchers can further ask if cross-national or primed difference is more due to the impact of individualism or to the impact of collectivism. The method lends itself to follow-up with studies examining the relative effect of components of individualism and collectivism and a comparison of the effect of individualism or collectivism and the effect of other cultural factors. It is worth reiterating that the logic here is not to isolate effects of individualism and collectivism from other related factors or confounds (e.g., gross national product, unemployment). Rather, by showing a change in effect when individualism is accessible and salient, compared to when collectivism is accessible and salient, or in comparison to control, the method allows for 
examination of these cultural factors even in the presence of other personal or societal concomitants.

Our review of the priming literature shows moderate-sized effects of primed individualism and collectivism in the direction suggested by the cross-national literature. Results move beyond this literature in two important ways. First, primed effects occur both in the East and the West. They are robust to variations in design characteristics such as use of different priming tasks and whether studies report results of priming both individualism and collectivism or report results for only one of these primes. In this way, even though the results are limited by the countries sampled and by a lack of nonstudent participants, they move beyond crossnational studies by suggesting that these effects of individualism and collectivism are not bound to specific contexts or meanings within particular societies and that they have causal effects on outcomes of interest.

Studies that included a direct comparison of cross-national (China, Germany) and primed effects provide direct evidence of the impact of the implied active ingredients of individualism and collectivism (Haberstroh et al., 2002). Studies that replicated priming effects across the East (Hong Kong) and West (U.S.) provide direct evidence that the primed active ingredients have general rather than country-specific effects (e.g., Aaker \& Lee, 2001; Briley \& Wyer, 2001; Gardner et al., 1999; Lee et al., 2000). A comparison of priming to control conditions suggests variable contributions of individualism and collectivism, depending on the outcome variable. An examination of effects also sheds light on gaps in the regional spread of research to date. Although Europe is represented, European data come mostly from Germany and the Netherlands. Scandinavian countries, which may differ due to larger egalitarian traditions, are not included; neither are Southern and Eastern Europe, which may differ in other ways. With regard to Eastern Europe, for example, recent political history may change the meaning of collectivism. Similarly, Latin American countries, countries with Islamic traditions, and African countries are woefully unrepresented. How individualism and collectivism are operationalized (and therefore what priming tasks are used) may well depend on which countries are used in imagining what is meant by individualism and collectivism. These gaps represent critical omissions.

Perhaps our understanding of collectivism is limited by the fact that the field has focused on the West and societies in the East that do not have ongoing within-society ethnic or tribal strife. How might things differ if research focused on collectivism within African and Middle Eastern contexts in which a culture of honor may combine with collectivism, rather than the culture of modesty suggested for Eastern collectivism (e.g., Nisbett, 2003)? To the extent that collectivism provides both in-group solidarity and also makes out-group boundaries salient, priming collectivism in countries with ongoing between-group conflict may focus attention on boundaries, not inclusion. Because in these countries cuing collectivism may cue boundaries, the cognitive procedures associated with collectivism may involve separating and contrasting, rather than the including and assimilating processes found cued in the extant priming and cross-national literature. To tease apart these issues, we must understand better both how collectivism works in other regions of the world, beyond the current focus on Western Europe/the U.S. and East Asia (especially China and Hong Kong), and which other cultural factors may overlap with collectivism.
This broader understanding will facilitate development of more targeted experimental tasks derived from more targeted models (e.g., models that distinguish uniqueness-focus from modestyfocus from honor-focus) to test these new assumptions and speculations.

Current findings allow some progress in model building, too, by suggesting that when salient and accessible, individualism and collectivism activate relevant knowledge and procedures or ways of thinking about the social and physical world. The cognitive tools or procedures that come to mind when individualism is cued focus on pulling apart and separating, contrasting figure from ground and self from other. The cognitive tools that come to mind when collectivism is cued focus on connecting and integrating, compromising, and assimilating figure with ground and self with other. This evidence goes beyond prior cross-national work and allows for tests of underlying processes.

Although generally supportive and consistently significant, the evidence also shows heterogeneity of effect by outcome variable and by prime. This heterogeneity is helpful because primes and outcome measures relate to theoretical conceptualizations of what the active ingredients of individualism and collectivism are and how individualism and collectivism matter in everyday contexts. Results are significant whether individualism and collectivism are primed by having participants sit alone or sit together, having them think about a Sumerian warrior who chose a general on the basis of skill or on the basis of family ties, or having participants circle singular versus plural personal pronouns, implying that individualism and collectivism can be variously cued.

Moreover, the fact that it is easy to document that (primed) individualism and (primed) collectivism both contribute to a shift in accessible cognitive procedures in the posited direction adds to the prior robust cross-national research demonstrating that differences in style exist across societies. Conversely, that it is difficult to document that (primed) individualism cues focus on the self as separate and independent of others provides a chance to reexamine implicit and explicit models of how cultural effects of individualism and collectivism are experienced at the individual level (e.g., Markus \& Kitayama, 1991; for an earlier critique see Matsumoto, 2002). Although self-concept is theoretically relevant and potentially the mediating process by which culture cues content and process knowledge, it is important to actually test that it is the self-concept specifically and not other procedural knowledge that is driving priming effects. For example, it would be helpful to test effects of the same priming tasks (e.g., scrambled sentence or subliminal prime) when the self is included or excluded from the priming materials and when more countries are included. If effects across societies are stronger when the self is included in the priming materials, this would lend stronger empirical support to the assumed mediation of individualism and collectivism effects via impact on self-concept (e.g., Kitayama, Duffy, \& Uchida, 2007; Markus \& Kitayama, 1991). If effects are not mediated by self-concept as currently measured when more countries are added, future research will need either to provide a better operationalization of relevant differences in self-concept or to suggest alternative mediating processes.

More generally, increased specification of cultural priming tasks would allow for disentangling which cognitive processes are universally cued when individualism or collectivism is cued and which processes are cued by individualism or collectivism only in 
particular societies. This would allow future research to examine both more universal process and processes likely rooted in particular modes or styles of being an individualist or a collectivist. By unpacking these effects, it would be possible to understand how the procedures cued by individualism and collectivism fit with overlapping but not identical procedures (e.g., global and local procedures, prevention and promotion procedures, abstract and concrete procedures). Some comparative research in this area is already being conducted. For example, Shavitt, Lalwani, Zhang, and Torelli (2006) used Triandis's conceptualization of horizontal and vertical individualism and collectivism to specify different effects within individualism and collectivism. They showed that adding this vertical specification clarifies cross-cultural differences. Although they have not attempted to isolate these effects through priming tasks, a number of relevant tasks for doing so have been proposed (Oyserman, 2006). These tasks would separate the effects of individualism and collectivism from the effects of power and perspectives on hierarchy. In our own lab, we have developed an integrative model that considers how multiple cultural factors may together account for cultural effects on psychological outcomes (Oyserman \& Lee, 2007, in press). More generally, by pitting different theoretical models against each other, future research can begin to address the extent to which crossnational differences are better attributed to some cultural factors than to others.

The stakes are high. As we engage more with others from different societies, intergroup conflict is not withering away in the modern age. A social cognition-based model that focuses on the immediate antecedents of salient and accessible active cultural frames can be helpful. After all, humans do much of their thinking in a social context, and the exploration of socially situated cognition is currently a main thrust of social psychological research, with cultural influences on social judgment emerging as an important aspect of this field (Schwarz, 2000). Because, as notably argued by William James (1890), thinking is for doing, it is reasonable to assume that social contexts provide a meaningmaking frame. Within this frame, some things seem obvious, easy, natural, and true; others do not. Within this frame, some of the multiple information processing strategies available to us are likely to be used; others are much less likely to be brought to mind (Schwarz, 2000; Taylor, 1998). Our current review supports the perspective that one of the ways in which meaning is organized in context is through the meaning provided by salient and accessible culture (operationalized as individualism and collectivism) and that once a particular cultural focus is cued, it is likely to carry with it relevant goals, motives, actions, ways of interpreting information, and processing strategies.

\section{References}

References marked with an asterisk indicate studies included in the meta-analysis.

*Aaker, J. L., \& Lee, A. Y. (2001). "I" seek pleasures and "we" avoid pains: The role of self-regulatory goals in information processing and persuasion. Journal of Consumer Research, 28, 33-49.

*Adaval, R., \& Cho, A. (2006). Cultural conflicts: How do threats to identity influence persuasion and behavior? Unpublished manuscript. China: Hong Kong University of Science and Technology.

Bargh, J. A. (1984). Automatic and controlled processing of social infor- mation. In R. S. Wyer, Jr. \& T. K. Srull (Eds.), Handbook of social cognition (Vol. 1, pp. 1-41). Hillsdale, NJ: Erlbaum.

Bargh, J. A. (2006). What have we been priming all these years? On the development, mechanisms, and ecology of nonconscious social behavior. European Journal of Social Psychology, 36, 147-168.

Bargh, J. A., Bond, R. N., Lombardi, W. J., \& Tota, M. E. (1986). The additive nature of chronic and temporary sources of construct accessibility. Journal of Personality and Social Psychology, 50, 869-878.

Bargh, J. A., \& Chartrand, T. L. (2000). The mind in the middle: A practical guide to priming and automaticity research. In H. T. Reis \& C. M. Judd (Eds.), Handbook of research methods in social and personality psychology (pp. 253-285). Cambridge, England: Cambridge University Press.

Biostat. (2005). Comprehensive meta-analysis (Version 2) [Computer software]. Englewood, NJ: Author.

Blondel, J., \& Inoguchi, T. (2006). Introduction: Political cultures in eighteen countries. In Political cultures in Asia and Europe: Citizens, states and societal values (pp. 1-19). New York: Routledge.

Bond, M. H., \& Leung, K. (in press). Cultural mapping of beliefs about the world and their application to a social psychology involving culture: Futurescaping. In C. Y. Chiu, Y. Y. Hong, S. Shavitt, \& R. S. Wyer, Jr. (Eds.), Problems and solutions in cross-cultural theory, research and application. New York: Psychology Press.

*Bond, M. H., \& Yang, K. S. (1982). Ethnic affirmation versus crosscultural accommodation: The variable impact of questionnaire language on Chinese bilinguals from Hong Kong. Journal of Cross-Cultural Psychology, 13, 169-185.

Bovasso, G. (1997). The interaction of depersonalization and deindividuation. Journal of Social Distress and the Homeless, 6, 213-228.

Brewer, M. B., \& Gardner, W. L. (1996). Who is this "we"? Levels of collective identity and self-representations. Journal of Personality and Social Psychology, 71, 83-93.

*Briley, D. A., \& Wyer, R. S. (2001). Transitory determinants of values and decisions: The utility (or nonutility) of individualism and collectivism in understanding cultural differences. Social Cognition, 19, $197-$ 227.

*Briley, D. A., \& Wyer, R. S. (2002). The effect of group membership salience on the avoidance of negative outcomes: Implications for social and consumer decisions. Journal of Consumer Research, 29, 400-415.

Chalfonte, B. L., \& Johnson, M. K. (1996). Feature memory and binding in young and older adults. Memory and Cognition, 24, 403-416.

Chartrand, T. L., \& Bargh, J. A. (1996). Automatic activation of impression formation: Nonconscious goal priming reproduces effects of explicit task instructions. Journal of Personality and Social Psychology, $71,464-478$.

Chen, S., Chen, K. Y., \& Shaw, L. (2004). Self-verification motives at the collective level of self-definition. Journal of Personality and Social Psychology, 86, 77-94.

Chiu, C. Y., Leung, A. K. Y., \& Kwan, L. (2007). Language, cognition, and culture: The Whorfian hypothesis and beyond. In S. Kitayama \& D. Cohen (Eds.), Handbook of cultural psychology (pp. 668-688). New York: Guilford Press.

Clayton, S. (2000). Models of justice in the environmental debate. Journal of Social Issues, 56, 459-474.

Cohen, J. (1988). Statistical power analysis for the behavioral sciences (2nd ed.). Hillsdale, NJ: Erlbaum.

Cook, T. D., \& Campbell, D. T. (1979). Quasi-experimentation: Design and analysis issues for field settings. Boston: Houghton-Mifflin.

Crisp, R. J., Hewstone, M., Richards, Z., \& Paolini, S. (2003). Inclusiveness and crossed categorization: Effects on co-joined category evaluations of in-group and out-group primes. British Journal of Social Psychology, 42, 25-38.

de Montes, L., Semin, G., \& Valencia, J. (2003). Communication patterns 
in interdependent relationships. Journal of Language and Social Psychology, 22, 259-281.

Duval, S. J., \& Tweedie, R. L. (2000a). A non-parametric "trim and fill" method of assessing publication bias in meta-analysis. Journal of the American Statistical Association, 95, 89-98.

Duval, S. J., \& Tweedie, R. L. (2000b). Trim and fill: A simple funnel plot based method of testing and adjusting for publication bias in metaanalysis. Biometrics, 56, 276-284.

Finlay, K. A., \& Trafimow, D. (1998). The relationship between the private self and helping victims of AIDS. Journal of Applied Social Psychology, 28, 1798-1809.

Fitzsimons, G. M., \& Kay, A. C. (2004). Language and interpersonal cognition: Causal effects of variations in pronoun usage on perceptions of closeness. Personality and Social Psychology Bulletin, 30, 547-557.

Förster, J., Liberman, N., \& Friedman, R. S. (2007). Seven principles of goal activation: A systematic approach to distinguishing goal priming from priming of non-goal constructs. Personality and Social Psychology Review, 11, 211-233.

Gaertner, L., Sedikides, C., \& Graetz, K. (1999). In search of selfdefinition: Motivational primacy of the individual self, motivational primacy of the collective self, or contextual primacy? Journal of Personality and Social Psychology, 76, 5-18.

*Gardner, W. L., Gabriel, S., \& Dean, K. K. (2004). The individual as "melting pot": The flexibility of bicultural self-construals. Cahiers de Psychologie Cognitive, 22, 181-201.

*Gardner, W. L., Gabriel, S., \& Hochschild, L. (2002). When you and I are "we," you are not threatening: The role of self-expansion in social comparison. Journal of Personality and Social Psychology, 82, 239251

*Gardner, W. L., Gabriel, S., \& Lee, A. Y. (1999). "I" value freedom, but "we" value relationships: Self-construal priming mirrors cultural differences in judgment. Psychological Science, 10, 321-326.

*Haberstroh, S., Oyserman, D., Schwarz, N., Kühnen, U., \& Ji, L. J. (2002). Is the interdependent self more sensitive to question context than the independent self? Self-construal and the observation of conversational norms. Journal of Experimental Social Psychology, 38, 323-329.

Hedges, L., \& Olkin, I. (1985). Statistical methods for meta-analysis. Orlando, FL: Academic Press.

Higgins, E. T. (1989). Knowledge accessibility and activation: Subjectivity and suffering from unconscious sources. In J. S. Uleman \& J. A. Bargh (Eds.), Unintended thought (pp. 75-123). New York: Guilford Press.

Higgins, E. T. (1996). Knowledge activation: Accessibility, applicability, and salience. In E. T. Higgins \& A. W. Kruglanski (Eds.), Social psychology: Handbook of basic principles (pp. 133-168). New York: Guilford Press.

Higgins, E. T., \& Bargh, J. A. (1987). Social cognition and social perception. Annual Review of Psychology, 38, 379-426.

Higgins, E. T., Rholes, W. S., \& Jones, C. R. (1977). Category accessibility and impression formation. Journal of Experimental Social Psychology, $13,141-154$.

Ho, D. Y. F. (1977). Culture-specific belief stereotypy and some of its personality, attitudinal, and intellective correlates. In Y. H. Poortinga (Ed.), Basic problems in cross-cultural psychology (pp. 289-298). Lisse, the Netherlands: Swets \& Zeitlinger.

Hofstede, G. (1980). Culture's consequences. Thousand Oaks, CA: Sage. Hofstede, G. (2001). Culture's consequences: Comparing values, behaviors, institutions and organizations across nations (2nd ed.). Thousand Oaks, CA: Sage.

*Holland, R. W., Roeder, U. R., van Baaren, R. B., Brandt, A. C., \& Hannover, B. (2004). Don't stand so close to me: The effects of selfconstrual on interpersonal closeness. Psychological Science, 15, 237242.

Horn, W. (1962). Leistungsprüfsystem, L-P-S: Handanweisung für die Durchführung, Auswertung und Interpretation [A performance testing system: Manual for administration, scoring, and interpretation]. Göttingen, Germany: Hogrefe-Verlag.

Inglehart, R. (1990). Culture shift in advanced industrial society. Princeton, NJ: Princeton University Press.

Inglehart, R. (1997). Modernization and postmodernization: Cultural, economic, and political change in 43 societies. Princeton, NJ: Princeton University Press.

Inglehart, R. (2000, Winter). Globalization and postmodern values. The Washington Quarterly, 23(1), 215-228.

Inglehart, R., \& Baker, W. (2000). Modernization, cultural change and the persistence of traditional values. American Sociological Review, 65, $19-51$.

Inglehart, R., \& Oyserman, D. (2004). Individualism, autonomy, and self-expression: The human development syndrome. In H. Vinken, J. Soeters, \& P. Ester (Eds.), Comparing cultures: Dimensions of culture in a comparative perspective (pp. 74-96). Leiden, the Netherlands: Brill. James, W. (1890). The principles of psychology. New York: Holt.

Jensen, A., \& Whang, P. (1994). Speed of accessing mathematical facts from long-term memory: A comparison of Chinese American and Anglo American children. Contemporary Educational Psychology, 19, 1-13.

Johnson, B. T. (1993). DSTAT 1.10: Software for the meta-analytic review of research literatures. Hillsdale, NJ: Erlbaum.

Johnson, B. T., \& Eagly, A. H. (2000). Quantitative synthesis in social psychological research. In H. T. Reis \& C. M. Judd (Eds.), Handbook of research methods in social and personality psychology (pp. 496-528). London: Cambridge University Press.

Kağıtçıbaşı, Ç. (1997). Whither multiculturalism? Applied Psychology: An International Review, 46(1), 44-49.

Kanagawa, C., Cross, S. E., \& Markus, H. R. (2001). "Who am I?" The cultural psychology of the conceptual self. Personality and Social Psychology Bulletin, 27, 90-103.

Kashima, Y., Kashima, E. S., \& Aldridge, J. (2001). Toward cultural dynamics of self-conceptions. In C. Sedikides \& M. B. Brewer (Eds.), Individual self, relational self, collective self (pp. 277-298). Philadelphia: Taylor \& Francis.

Kelley, H. H. (1955). Salience of membership and resistance to change of group-anchored attitudes. Human Relations, 8, 275-289.

*Kemmelmeier, M. (2003). Individualism and attitudes toward affirmative action: Evidence from priming experiments. Basic and Applied Social Psychology, 25, 111-119.

*Kemmelmeier, M., \& Cheng, B. (2004). Language and self-construal priming: A replication and extension in a Hong Kong sample. Journal of Cross-Cultural Psychology, 35, 705-712.

*Kemmelmeier, M., Wieczorkowska, G., Erb, H. P., \& Burstein, E. (2002). Individualism, authoritarianism, and attitudes toward assisted death: Cross-cultural, cross-regional, and experimental evidence. Journal of Applied Social Psychology, 32, 60-85.

Kitayama, S., Duffy, S., Kawamura, T., \& Larsen, J. (2003). Perceiving an object and its context in different cultures. Psychological Science, 14, 201-206.

Kitayama, S., Duffy, S., \& Uchida, Y. (2007). Self as cultural mode of being. In S. Kitayama \& D. Cohen (Eds.), Handbook of cultural psychology (pp. 136-174). New York: Guilford Press.

Kuhn, M. H., \& McPartland, T. S. (1954). An empirical investigation of self-attitudes. American Sociological Review, 19, 68-76.

*Kühnen, U., \& Haberstroh, S. (2004). Self-construal activation and focus of comparison as determinants of assimilation and contrast in social comparisons. Cahiers de Psychologie Cognitive, 22, 289-310.

*Kühnen, U., \& Hannover, B. (2000). Assimilation and contrast in social comparisons as a consequence of self-construal activation. European Journal of Social Psychology, 30, 799-811.

*Kühnen, U., Hannover, B., \& Schubert, B. (2001). The semanticprocedural interface model of the self: The role of self-knowledge for 
context-dependent versus context-independent modes of thinking. Journal of Personality and Social Psychology, 80, 397-409.

*Kühnen, U., \& Oyserman, D. (2002). Thinking about the self influences thinking in general: Cognitive consequences of salient self-concept. Journal of Experimental Social Psychology, 38, 492-499.

*Lee, A. Y., Aaker, J. L., \& Gardner, W. L. (2000). The pleasures and pains of distinct self-construals: The role of interdependence in regulatory focus. Journal of Personality and Social Psychology, 78, 11221134.

Leung, T., \& Kim, M. S. (1997). A revised self-construal scale. Honolulu: University of Hawaii at Monoa.

*Levine, T. R., Bresnahan, M. J., Park, H. S., Lapinski, M., Wittenbaum, G., Shearman, S., et al. (2003). Self-construal scales lack validity. Human Communication Research, 29, 210-252.

Lipsey, M. W., \& Wilson, D. B. (2001). Practical meta-analysis. Thousand Oaks, CA: Sage.

Liu, I. M. (1986). Chinese cognition. In M. H. Bond (Ed.), The psychology of the Chinese people (pp. 73-105). New York: Oxford University Press.

*Lockwood, P., Dolderman, D., Sadler, P., \& Gerchak, E. (2004). Feeling better about doing worse: Social comparisons within romantic relationships. Journal of Personality and Social Psychology, 87, 80-95.

Maass, A., Karasawa, M., Politi, F., \& Suga, S. (2006). Do verbs and adjectives play different roles in different cultures? A cross-linguistic analysis of person representation. Journal of Personality and Social Psychology, 90, 734-750.

*Mandel, N. (2003). Shifting selves and decision making: The effects of self-construal priming on consumer risk-taking. Journal of Consumer Research, 30, 30-40.

*Marian, V., \& Kaushanskaya, M. (2004). Self-construal and emotion in bicultural bilinguals. Journal of Memory and Language, 51, 190-201.

Markus, H. R., \& Kitayama, S. (1991). Culture and the self: Implications for cognition, emotion, and motivation. Psychological Review, 98, 224253

Matsumoto, D. (2002). The new Japan: Debunking seven cultural stereotypes. Yarmouth, ME: Intercultural Press.

McFarland, C., \& Beuhler, R. (1995). Collective self-esteem as a moderator of the frog-pond effect in relation to performance feedback. Journal of Personality and Social Psychology, 68, 1055-1070.

Miller, J. G., Bersoff, D. M., \& Harwood, R. L. (1990). Perceptions of social responsibilities in India and in the United States: Moral imperatives or personal decisions? Journal of Personality and Social Psychology, 58, 33-47.

Mussweiler, T., \& Bodenhausen, G. V. (2002). I know you are, but what am I? Self-evaluative consequences of judging in-group and out-group members. Journal of Personality and Social Psychology, 82, 19-31.

Neely, J. H. (1977). Semantic priming and retrieval from lexical memory: Roles of inhibitionless spreading activation and limited-capacity attention. Journal of Experimental Psychology: General, 106, 226-254.

Nisbett, R. E. (2003). The geography of thought: How Asians and Westerners think differently. . and why. New York: Free Press.

Nisbett, R. E., \& Cohen, D. (1996). Culture of honor: The psychology of violence in the South. Boulder, CO: Westview Press.

Norenzayan, A., Choi, I., \& Peng, K. (2007). Perception and cognition. In S. Kitayama \& D. Cohen (Eds.), Handbook of cultural psychology (pp. 569-594). New York: Guilford Press.

*Oishi, S., Wyer, R., \& Colcombe, S. (2000). Cultural variation in the use of current life satisfaction to predict the future. Journal of Personality and Social Psychology, 78, 434-445.

Oyserman, D. (2006). High power, low power, and equality: Culture beyond individualism and collectivism. Journal of Consumer Psychology, 16, 352-356.

Oyserman, D., Coon, H., \& Kemmelmeier, M. (2002). Rethinking individualism and collectivism: Evaluation of theoretical assumptions and meta-analyses. Psychological Bulletin, 128, 3-72.
Oyserman, D., Kemmelmeier, M., \& Coon, H. (2002). Cultural psychology, a new look: Reply to Bond (2002), Fiske (2002), Kitayama (2002), and Miller (2002). Psychological Bulletin, 128, 110-117.

Oyserman, D., \& Lee, S. W. S. (2007). Priming "culture": Culture as situated cognition. In S. Kitayama and D. Cohen (Eds.), Handbook of cultural psychology (pp. 255-279). New York: Guilford Press.

Oyserman, D., \& Lee, S. W. S. (in press). A situated cognition perspective on culture: Effects of priming cultural syndromes on cognition and motivation. In R. Sorrentino \& S. Yamaguchi (Eds.), Handbook of motivation and cognition across cultures. New York: Elsevier.

Oyserman, D., Sorensen, N., Reber, R., Sannum, P., \& Chen, S. (2008). What did you say? What did you say? "I" pay attention to one thing; "We" listen to everything. Unpublished manuscript. University of Michigan, Ann Arbor.

*Ralston, D. A., Cunniff, M. K., \& Gustafson, D. J. (1995). Cultural accommodation: The effect of language on the responses of bilingual Hong Kong Chinese managers. Journal of Cross-Cultural Psychology, 26, 714-727.

Reed, A. (2004). Activating the self-importance of consumer selves: Exploring identity salience effects on judgments. Journal of Consumer Research, 31, 286-295.

Rokeach, M. (1973). The nature of human values. New York: Free Press.

Rosenberg, M. (1965). Society and the adolescent self-image. Princeton, NJ: Princeton University Press.

Rosenthal, R. (1979). The file drawer problem and tolerance for null results. Psychological Bulletin, 86, 638-641.

Rosenthal, R. (1995). Writing meta-analytic reviews. Psychological Bulletin, 118, 183-192.

*Ross, M., Xun, W. Q. E., \& Wilson, A. E. (2002). Language and the bicultural self. Personality and Social Psychology Bulletin, 28, 10401050 .

Schwartz, S. H. (1990). Individualism-collectivism: Critique and proposed refinements. Journal of Cross-Cultural Psychology, 21, 139-157.

Schwartz, S. H. (1992). Universals in the content and structure of values: Theoretical advances and empirical tests in 20 countries. In M. P. Zanna (Ed.), Advances in experimental social psychology (Vol. 25, pp. 1-65). New York: Academic Press.

Schwartz, S. H., \& Bilsky, W. (1987). Toward a universal psychological structure of human values. Journal of Personality and Social Psychology, $53,550-562$.

Schwarz, N. (2000). Social judgment and attitudes: Warmer, more social, and less conscious. European Journal of Social Psychology, 30, 149176.

Schwarz, N. (2002). Situated cognition and the wisdom of feelings: Cognitive tuning. In L. F. Barrett \& P. Salovey (Eds.), The wisdom in feelings: Psychological processes in emotional intelligence (pp. 144166). New York: Guilford Press.

Schwarz, N. (2006). Attitude research: Between Ockham's Razor and the fundamental attribution error. Journal of Consumer Psychology, 33, $19-21$.

Schwarz, N., \& Brand, J. F. (1983). Effects of salience of rape on sex role attitudes, trust, and self-esteem in non-raped women. European Journal of Social Psychology, 13, 71-76.

Schwarz, N., \& Strack, F. (1981). Manipulating salience: Causal assessment in natural settings. Personality and Social Psychology Bulletin, 7, $554-558$.

Semin, G. (2000). Agenda 2000-Communication: Language as an implementational device for cognition. European Journal of Social Psychology, 29, 484-501

Semin, G., Görts, C., Nandram, S., \& Semin-Goossens, A. (2002). Cultural perspectives on the linguistic representation of emotion and emotion events. Cognition and Emotion, 16, 11-28.

Shavitt, S., Lalwani, A. K., Zhang, J., \& Torelli, C. J. (2006). The 
horizontal/vertical distinction in cross-cultural consumer research. Journal of Consumer Psychology, 16, 325-342.

Singelis, T. M. (1994). The measurement of independent and interdependent self-construals. Personality and Social Psychology Bulletin, 20, $580-591$.

Srull, T. K., \& Wyer, R. S. (1978). Category accessibility and social perception. Journal of Personality and Social Psychology, 37, 841-856.

Srull, T. K., \& Wyer, R. S. (1979). The role of category accessibility in the interpretation of information about persons: Some determinants and implications. Journal of Personality and Social Psychology, 37, 16601672.

*Stapel, D. A., \& Koomen, W. (2001). I, we, and the effects of others on me: How self-construal level moderates social comparison effects. Journal of Personality and Social Psychology, 80, 766-781.

Stapel, D., \& Semin, G. (2007). The magic spell of language: Linguistic categories and their perceptual consequences. Journal of Personality and Social Psychology, 93, 23-33.

Stapel, D. A., \& Tesser, A. (2001). Self-activation increases social comparison. Journal of Personality and Social Psychology, 81, 742-750.

Sutton, A. J., Song, F., Gilbody, S. M., \& Abrams, K. R. (2000). Modeling publication bias in meta-analysis: A review. Statistical Methods in Medical Research, 9, 421-445.

Tajfel, H. (1982). Social psychology of intergroup relations. Annual Review of Psychology, 33, 1-39.

Tajfel, H. (2001). Social stereotypes and social groups. In. M. A. Hogg \& D. Abrams (Eds.), Intergroup relations: Essential readings (pp. 132145). New York: Psychology Press.

Tajfel, H., \& Forgas, J. (2000). Social categorization: Cognitions, values and groups. In C. Stangor (Ed.), Stereotypes and prejudice: Essential readings (pp. 49-63). New York: Psychology Press.

Tajfel, H., \& Turner, J. C. (2004). The social identity theory of intergroup behavior. In J. Jost \& J. Sidanius (Eds.), Political psychology: Key readings (pp. 276-293). New York: Psychology Press.

*Tavassoli, N. T. (2002). Spatial memory for Chinese and English. Journal of Cross-Cultural Psychology, 33, 415-431.

Taylor, S. E. (1998). The social being in social psychology. In D. Gilbert, S. Fiske, \& G. Lindzey (Eds.), Handbook of social psychology (4th ed., Vol. 1, pp. 58-95). New York: McGraw-Hill.

Taylor, S. E., \& Fiske, S. T. (1978). Salience, attention, and attribution: Top of the head phenomena. Advances in Experimental Social Psychology, 11, 249-288.

Tewes, U. (1994). HAWIE-R: Hamburg-Wechsler-Intelligenztest für Erwachsene, Revision 1991: Handbuch und Testanweisung [HAWIE-R: Hamburg-Wechsler Intelligence Test for Adults, Revision 1991: Test manual] (2nd ed.). Bern, Switzerland: Huber.

*Trafimow, D., Silverman, E. S., Fan, R. M. T., \& Law, J. S. F. (1997). The effects of language and priming on the relative accessibility of the private self and the collective self. Journal of Cross-Cultural Psychology, 28, 107-123.

*Trafimow, D., \& Smith, M. D. (1998). An extension of the "two-baskets" theory to Native Americans. European Journal of Social Psychology, 28, 1015-1019.

*Trafimow, D., Triandis, H., \& Goto, S. (1991). Some tests of the distinction between the private self and the collective self. Journal of Personality and Social Psychology, 60, 649-655.

Triandis, H. C. (1988). Collectivism vs. individualism: A reconceptualization of a basic concept in cross-cultural social psychology. In G. K. Verma \& C. Bagley (Eds.), Cross-cultural studies of personality, attitudes and cognition (pp. 60-95). New York: St. Martin Press.

Triandis, H. C. (1989). Cross-cultural studies of individualism and collectivism. In R. A. Dienstbier \& J. J. Berman (Eds.), Nebraska Symposium on Motivation: Vol. 37. Cross-cultural perspectives (pp. 41-133). Lincoln: University of Nebraska Press.
Triandis, H. C. (1995). Individualism and collectivism. Boulder, CO: Westview Press.

Triandis, H. C. (1996). The psychological measurement of cultural syndromes. American Psychologist, 51, 407-415.

Triandis, H. C. (2007). Culture and psychology: A history of the study of their relationship. In S. Kitayama \& D. Cohen (Eds.), Handbook of cultural psychology (pp. 59-76). New York: Guilford Press.

Triandis, H. C., \& Gelfand, M. J. (1998). Converging measurement of horizontal and vertical individualism and collectivism. Journal of Personality and Social Psychology, 74, 118-128.

Triandis, H. C., McCusker, C., \& Hui, C. H. (1990). Multimethod probes of individualism and collectivism. Journal of Personality and Social Psychology, 59, 1006-1020.

Triandis, H. C., \& Trafimow, D. (2001). Cross-national prevalence of collectivism. In C. Sedikides \& M. B. Brewer (Eds.), Individual self, relational self, collective self (pp. 259-276). Philadelphia: Taylor \& Francis.

*Utz, S. (2004a). Self-activation is a two-edged sword: The effects of $I$ primes on cooperation. Journal of Experimental Social Psychology, 40, $769-776$.

*Utz, S. (2004b). Self-construal and cooperation: Is the interdependent self more cooperative than the independent self? Self and Identity, 3, 177190.

*van Baaren, R. B., Maddux, W. W., Chartrand, T. L., de Bouter, C., \& van Knippenberg, A. (2003). It takes two to mimic: Behavioral consequences of self-construals. Journal of Personality and Social Psychology, 84, 1093-1102.

*Vohs, K. D., \& Heatherton, T. F. (2001). Self-esteem and threats to self: Implications for self-construals and interpersonal perceptions. Journal of Personality and Social Psychology, 81, 1103-1118.

Vorauer, J., \& Cameron, J. (2002). So close, and yet so far: Does collectivism foster transparency overestimation? Journal of Personality and Social Psychology, 83, 1344-1352.

Wang, Q., \& Ross, M. (2007). Culture and memory. In S. Kitayama \& D. Cohen (Eds.), Handbook of cultural psychology (pp. 645-667). New York: Guilford Press.

*Watkins, D., \& Gerong, A. (1999). Language of response and the spontaneous self-concept: A test of the cultural accommodation hypothesis. Journal of Cross-Cultural Psychology, 30, 115-121.

*Watkins, D., \& Regmi, M. (2002). Does the language of response influence self-presentation? A Nepalese test of the cultural accommodation hypothesis. Psychologia: An International Journal of Psychology in the Orient, 45, 98-103.

Watson, D., Clark, L. A., \& Tellegen, A. (1988). Development and validation of brief measures of positive and negative affect: The PANAS scales. Journal of Personality and Social Psychology, 54, 1063-1070.

*Wenzel, M. (2002). What is social about justice? Inclusive identity and group values as the basis of the justice motive. Journal of Experimental Social Psychology, 38, 205-218.

Wit, A. P., \& Kerr, N. L. (2002). "Me versus just us versus us all" categorization and cooperation in nested social dilemmas. Journal of Personality and Social Psychology, 83, 616-637.

Witkin, H. A., Oltman, P. K., Raskin, E., \& Karp, S. A. (1971). Manual for the Embedded Figures Test, Children's Embedded Figures Test, and Group Embedded Figures Test. Palo Alto, CA: Consulting Psychologists Press.

*Yang, K. S., \& Bond, M. H. (1980). Ethnic affirmation by Chinese bilinguals. Journal of Cross-Cultural Psychology, 11, 411-425.

*Ybarra, O., \& Trafimow, D. (1998). How priming the private self or collective self affects the relative weights of attitudes and subjective norms. Personality and Social Psychology Bulletin, 24, 362-370. 


\section{Appendix A}

Table A1

Values Studies Used in the Meta-Analysis

\begin{tabular}{|c|c|c|c|c|c|}
\hline $\begin{array}{l}\text { Studies organized by } \\
\text { priming task and level } \\
\text { of collectivism primed }\end{array}$ & $\begin{array}{l}\text { Sample is undergraduates unless } \\
\text { otherwise specified (Language) }\end{array}$ & Measure & $\begin{array}{l}\text { Expected individualism } \\
\text { prime effect }\end{array}$ & $\begin{array}{l}\text { Expected collectivism } \\
\text { prime effect }\end{array}$ & $\begin{array}{l}\text { Effect size } \\
\quad(d)\end{array}$ \\
\hline \multicolumn{6}{|c|}{ European heritage } \\
\hline \multicolumn{6}{|c|}{ Relational collectivism } \\
\hline \multirow{2}{*}{$\begin{array}{l}\text { Pronoun circling task } \\
\text { Gardner et al. (2004) }\end{array}$} & & & & & \\
\hline & $\begin{array}{l}24 \text { European Americans } \\
\text { (English) }\end{array}$ & $\begin{array}{l}\text { Schwartz (1992); } \\
\text { Triandis et al. } \\
\text { (1990) }\end{array}$ & Endorse IND values & Endorse COL values & 0.28 \\
\hline $\begin{array}{l}\text { Gardner et al. (1999, } \\
\text { Study 1) }\end{array}$ & $\begin{array}{l}45 \text { European Americans } \\
\text { (English) }\end{array}$ & $\begin{array}{l}\text { Schwartz (1992); } \\
\text { Triandis et al. } \\
\text { (1990) }\end{array}$ & Endorse IND values & Endorse COL values & 0.24 \\
\hline \multicolumn{6}{|c|}{ SDFF-based task: Writing an I- or we-personalized paragraph } \\
\hline $\begin{array}{l}\text { Kemmelmeier et al. } \\
\text { (2002, Study } 3)\end{array}$ & 72 U.S. (English) & $\begin{array}{l}\text { Attitude about } \\
\text { physician-assisted } \\
\text { suicide }\end{array}$ & $\begin{array}{l}\text { Value individual } \\
\text { choice more }\end{array}$ & $\begin{array}{l}\text { Value individual } \\
\text { choice less }\end{array}$ & 0.54 \\
\hline \multicolumn{6}{|c|}{ Both relational and collective group-based collectivism } \\
\hline Sumerian warrior story & & & & & \\
\hline $\begin{array}{l}\text { Gardner et al. (1999, } \\
\text { Study 1) }\end{array}$ & $\begin{array}{l}45 \text { European Americans } \\
\text { (English) }\end{array}$ & $\begin{array}{l}\text { Schwartz (1992); } \\
\text { Triandis et al. } \\
\text { (1990) }\end{array}$ & Endorse IND values & Endorse COL values & 0.24 \\
\hline $\begin{array}{l}\text { Gardner et al. (1999, } \\
\text { Study 2) }\end{array}$ & $\begin{array}{l}50 \text { European Americans } \\
\text { (English) }\end{array}$ & $\begin{array}{l}\text { Schwartz (1992); } \\
\text { Triandis et al. } \\
\text { (1990) }\end{array}$ & Endorse IND values & Endorse COL values & 0.94 \\
\hline $\begin{array}{l}\text { Scrambled sentence task } \\
\text { Briley \& Wyer (2001, } \\
\text { Study 4) }\end{array}$ & 33 U.S. (English) & Triandis (1995) & $\begin{array}{l}\text { Endorse IND values } \\
\text { more, COL values } \\
\text { less }\end{array}$ & $\begin{array}{l}\text { Endorse IND values } \\
\text { less, COL values } \\
\text { more }\end{array}$ & 0.12 \\
\hline
\end{tabular}

Group imagination task (solo vs. team tennis match) Lee et al. (2000, Study 72 U.S. (English) 2)

Lee et al. (2000, Study 98 U.S. (English) 3)

Lee et al. (2000, Study 65 U.S. (English) 4)
Collective group-based collectivism

$\begin{array}{cc}\text { Perceived importance } & \begin{array}{c}\text { Value promotion } \\ \text { situation } \\ \text { Perceived importance } \\ \text { Value promotion } \\ \text { situation } \\ \text { Perceived importance }\end{array} \\ \begin{array}{c}\text { Value promotion } \\ \text { situation }\end{array}\end{array}$

$\begin{array}{lc}\begin{array}{l}\text { Value prevention } \\ \text { situation }\end{array} & 0.52 \\ \begin{array}{l}\text { Value prevention } \\ \text { situation }\end{array} & 0.55 \\ \begin{array}{l}\text { Value prevention } \\ \text { situation }\end{array} & 0.72 \\ \end{array}$

Asian North American heritage

Relational collectivism

Pronoun circling task Gardner et al. (2004)
22 Asian Americans (English)
Schwartz (1992); $\quad$ Endorse IND values Triandis et al. (1990)


Table A1 (continued)

Studies organized by priming task and level of collectivism primed
Sample is undergraduates unless otherwise specified (Language)

Measure

Effect

$\begin{array}{ll}\text { Expected individualism } & \text { Expected collectivism } \\ \text { size }\end{array}$ prime effect prime effect

Collective group-based collectivism

Group instantiation task

Briley \& Wyer (2002,

Study 1)

Briley \& Wyer (2002,

Study 3)

Group imagination task (solo vs. team tennis match)

Lee et al. (2000, Study 117 Hong Kong Chinese

3)

Lee et al. (2000, Study 4)
46 Hong Kong Chinese (English)

93 Hong Kong Chinese (English)

83 Hong Kong Chinese (Chinese)

Equality-related
proverbs
Equality-related
proverbs

Perceived importance

Perceived importance

\section{Endorse less}

Endorse less

Value promotion situation

Value promotion situation
Endorse more

Endorse more

Value prevention situation

Value prevention situation

Language prime (Assume English as individualism prime; Chinese as collectivism prime)

Bond \& Yang (1982)

Ralston et al. (1995)

Ross et al. (2002)

Yang \& Bond (1980)

184 Hong Kong Chinese males (92 English, 92 Chinese)
104 Hong Kong managers (52 English, 52 Chinese) ${ }^{a}$

52 Chinese living in Canada mostly from Hong Kong (29 English, 23 Chinese) ${ }^{\mathrm{b}}$

\section{Belief stereotypy scale (Ho, 1977); \\ Chineseness (Yang \\ \& Bond, 1980); \\ Rokeach Value \\ Survey (Rokeach, \\ 1973)}

Schwartz (1992)

Chinese cultural views

Chinese practices
Less belief stereotypy,

Chineseness,

Chinese values

Endorse IND values

Endorse less

121 Hong Kong Chinese (60 English, 61 Chinese)

Note. Participants are described in the detail available in the published article; where only country is known, this information is provided (e.g., U.S.). If the sample is described with regard to race/ethnicity (e.g., European American), this information is provided. IND = individualism; COL $=$ collectivism; $\mathrm{SDFF}=$ similarities and differences with family and friends task.

${ }^{a}$ Only Hong Kong participants $(n=104)$ were language-primed (English vs. Chinese) and included in computing the language prime effect. U.S. data were excluded. $\quad{ }^{\mathrm{b}}$ Only Chinese-born participants $(n=52)$ were language-primed (English vs. Chinese) and included in computing the language prime effect. Canadian data were excluded. 
Table A2

Self-Concept Studies Used in the Meta-Analysis

\begin{tabular}{|c|c|c|c|c|c|}
\hline $\begin{array}{l}\text { Studies organized by priming task } \\
\text { and level of collectivism primed }\end{array}$ & $\begin{array}{c}\text { Sample is undergraduates } \\
\text { unless otherwise } \\
\text { specified (Language) }\end{array}$ & Measure & $\begin{array}{l}\text { Expected individualism } \\
\text { prime effect }\end{array}$ & $\begin{array}{l}\text { Expected collectivism } \\
\text { prime effect }\end{array}$ & $\begin{array}{l}\text { Effect size } \\
\qquad(d)\end{array}$ \\
\hline \multicolumn{6}{|c|}{ European heritage } \\
\hline \multicolumn{6}{|c|}{ Relational collectivism } \\
\hline \multicolumn{6}{|l|}{ Pronoun circling task } \\
\hline Gardner et al. (2004) & $\begin{array}{l}24 \text { European Americans } \\
\text { (English) }\end{array}$ & TST & $\begin{array}{l}\text { More independent self- } \\
\text { descriptions }\end{array}$ & $\begin{array}{l}\text { More interdependent } \\
\text { \& collective self- } \\
\text { descriptions }\end{array}$ & 0.89 \\
\hline Gardner et al. (1999, Study 1) & $\begin{array}{l}45 \text { European Americans } \\
\text { (English) }\end{array}$ & TST & $\begin{array}{l}\text { More independent self- } \\
\text { descriptions }\end{array}$ & $\begin{array}{l}\text { More interdependent } \\
\& \text { collective self- } \\
\text { descriptions }\end{array}$ & 0.88 \\
\hline Levine et al. (2003, Study 1) & $\begin{array}{l}121 \text { U.S. (102 European } \\
\text { Americans) (English) }\end{array}$ & SCS & $\begin{array}{l}\text { More independent self- } \\
\text { descriptions }\end{array}$ & $\begin{array}{l}\text { More interdependent } \\
\text { \& collective self- } \\
\text { descriptions }\end{array}$ & 0.17 \\
\hline Levine et al. (2003, Study 2) & $\begin{array}{l}49 \text { European Americans } \\
\text { (English) }\end{array}$ & SCS & $\begin{array}{l}\text { More independent self- } \\
\text { descriptions }\end{array}$ & $\begin{array}{l}\text { More interdependent } \\
\text { \& collective self- } \\
\text { descriptions }\end{array}$ & -0.09 \\
\hline Levine et al. (2003, Study 3) & $\begin{array}{l}361 \text { U.S. (303 European } \\
\text { Americans) (English) }\end{array}$ & SCS & $\begin{array}{l}\text { More independent self- } \\
\text { descriptions }\end{array}$ & $\begin{array}{l}\text { More interdependent } \\
\& \text { collective self- } \\
\text { descriptions }\end{array}$ & -0.05 \\
\hline Trafimow et al. (1991, Study 1) & 24 Americans (English) & TST & $\begin{array}{l}\text { More independent self- } \\
\text { descriptions }\end{array}$ & $\begin{array}{l}\text { More collective self- } \\
\text { descriptions }\end{array}$ & 0.42 \\
\hline Kühnen et al. (2001, Study 2) & 76 Germans (German) & $\begin{array}{l}\text { SCS modified (3- } \\
\text { item; Singelis, } \\
\text { 1994) }\end{array}$ & $\begin{array}{l}\text { More context- } \\
\text { independent self- } \\
\text { descriptions }\end{array}$ & $\begin{array}{l}\text { More context- } \\
\text { dependent self- } \\
\text { descriptions }\end{array}$ & 0.53 \\
\hline Vohs \& Heatherton (2001, Study 3) & 23 U.S. women (English) & TST & $\begin{array}{l}\text { More independent self- } \\
\text { descriptions }\end{array}$ & $\begin{array}{l}\text { More interdependent } \\
\text { \& collective self- } \\
\text { descriptions }\end{array}$ & 0.44 \\
\hline \multicolumn{6}{|c|}{ Unclassified task: reading about self or family drinking grape juice } \\
\hline $\begin{array}{l}\text { Aaker \& Lee (2001, Study } 1 \\
\quad \text { pretest) }\end{array}$ & 51 U.S. (English) & $\begin{array}{l}\text { Thoughts about self } \\
\& \text { others }\end{array}$ & More independent & $\begin{array}{l}\text { More interdependent } \\
\text { (including family) }\end{array}$ & 0.22 \\
\hline \multicolumn{6}{|c|}{ Both relational and collective group-based collectivism } \\
\hline \multicolumn{6}{|l|}{ Sumerian warrior story } \\
\hline $\begin{array}{l}\text { Gardner et al. (2002, Study } 2 \\
\text { Pretest) }\end{array}$ & $\begin{array}{l}62 \text { U.S. ( } 35 \text { women, } 27 \\
\text { men) (English) }\end{array}$ & $\begin{array}{l}\text { TST modified (6- } \\
\text { item) }\end{array}$ & $\begin{array}{l}\text { Fewer collective self- } \\
\text { descriptions }\end{array}$ & $\begin{array}{l}\text { More collective self- } \\
\text { descriptions }\end{array}$ & 0.67 \\
\hline Gardner et al. (1999, Study 1) & $\begin{array}{l}45 \text { European Americans } \\
\text { (English) }\end{array}$ & TST & $\begin{array}{l}\text { More independent self- } \\
\text { descriptions }\end{array}$ & $\begin{array}{l}\text { More interdependent } \\
\text { \& collective self- } \\
\text { descriptions }\end{array}$ & 0.88 \\
\hline Levine et al. (2003, Study 2) & $\begin{array}{l}50 \text { European Americans } \\
\text { (English) }\end{array}$ & SCS & More independent & $\begin{array}{l}\text { More interdependent } \\
\text { \& collective }\end{array}$ & -0.09 \\
\hline Trafimow et al. (1991, Study 2) & 48 U.S. (English) & TST & $\begin{array}{l}\text { More independent self- } \\
\text { descriptions }\end{array}$ & $\begin{array}{l}\text { More collective self- } \\
\text { descriptions }\end{array}$ & 0.42 \\
\hline \multicolumn{6}{|c|}{ Collective group-based collectivism } \\
\hline \multicolumn{6}{|c|}{ Group imagination task (solo vs. team tennis match) } \\
\hline Aaker \& Lee (2001, Study 2 pretest) & 19 U.S. (English) & $\begin{array}{l}\text { Thoughts about self } \\
\text { \& others }\end{array}$ & More independent & $\begin{array}{l}\text { More collective } \\
\text { (including } \\
\text { teammates) }\end{array}$ & 0.43 \\
\hline Lee et al. (2000, Study 2) & 72 U.S. (English) & $\begin{array}{l}\text { Thoughts about self } \\
\text { \& others }\end{array}$ & More independent & $\begin{array}{l}\text { More collective } \\
\text { (including } \\
\text { teammates) }\end{array}$ & 0.27 \\
\hline Lee et al. (2000, Study 3) & 98 U.S. (English) & $\begin{array}{l}\text { Thoughts about self } \\
\text { \& others }\end{array}$ & More independent & $\begin{array}{l}\text { More collective } \\
\text { (including } \\
\text { teammates) }\end{array}$ & 0.48 \\
\hline Lee et al. (2000, Study 4) & 65 U.S. (English) & $\begin{array}{l}\text { Thoughts about self } \\
\text { \& others }\end{array}$ & More independent & $\begin{array}{l}\text { More collective } \\
\text { (including } \\
\text { teammates) }\end{array}$ & 0.42 \\
\hline
\end{tabular}

American Indian or Native American heritage

Sumerian warror story

Trafimow \& Smith (1998)

Both relational and collective group-based collectivism

62 U.S. Native
Americans, mixed
students, and other

adults (English)
TST

More independent selfdescriptions
More collective selfdescriptions
0.32 
Table A2 (continued)

\begin{tabular}{|c|c|c|c|c|c|}
\hline $\begin{array}{l}\text { Studies organized by priming task } \\
\text { and level of collectivism primed }\end{array}$ & $\begin{array}{c}\text { Sample is undergraduates } \\
\text { unless otherwise } \\
\text { specified (Language) }\end{array}$ & Measure & $\begin{array}{l}\text { Expected individualism } \\
\text { prime effect }\end{array}$ & $\begin{array}{l}\text { Expected collectivism } \\
\text { prime effect }\end{array}$ & $\begin{array}{l}\text { Effect size } \\
\qquad(d)\end{array}$ \\
\hline \multicolumn{6}{|c|}{ Asian North American heritage } \\
\hline \multicolumn{6}{|c|}{ Relational collectivism } \\
\hline \multicolumn{6}{|l|}{ Pronoun circling task } \\
\hline Gardner et al. (2004) & $\begin{array}{l}22 \text { Asian Americans } \\
\text { (Chinese, Korean, \& } \\
\text { Japanese) (English) }\end{array}$ & TST & $\begin{array}{l}\text { More independent self- } \\
\text { descriptions }\end{array}$ & $\begin{array}{l}\text { More interdependent } \\
\& \text { collective self- } \\
\text { descriptions }\end{array}$ & 2.18 \\
\hline Trafimow et al. (1991, Study 1) & $\begin{array}{l}18 \text { Chinese in U.S. } \\
\text { (English) }\end{array}$ & TST & $\begin{array}{l}\text { More independent self- } \\
\text { descriptions }\end{array}$ & $\begin{array}{l}\text { More collective self- } \\
\text { descriptions }\end{array}$ & 0.32 \\
\hline
\end{tabular}

Asian heritage

Pronoun circling task

Trafimow et al. (1997)
63 Hong Kong Chinese college and high school students $(20$ English, 43 Chinese)

Relational collectivism

\begin{tabular}{|c|c|c|}
\hline TST & $\begin{array}{l}\text { More independent self- } \\
\text { descriptions }\end{array}$ & $\begin{array}{l}\text { More collective self- } \\
\text { descriptions }\end{array}$ \\
\hline
\end{tabular}

Both relational and collective group-based collectivism

Sumerian warrior story

Trafimow et al. (1997)
61 Hong Kong Chinese TST college and high school students (21

English, 40 Chinese)
TST

More independent
descriptions

More collective self- $\quad 0.09$ descriptions

Collective group-based collectivism

Group imagination task (solo vs. team tennis match)

$\begin{array}{cc}\begin{array}{c}\text { Aaker \& Lee (2001, Study } 2 \\ \text { pretest) }\end{array} & \text { (English) }\end{array}$

Lee et al. (2000, Study 3)

Lee et al. (2000, Study 4)
117 Hong Kong Chinese (Chinese)

83 Hong Kong Chinese (Chinese)
Thoughts about self More independent $\&$ others

Thoughts about self More independent $\&$ others

Thoughts about self More independent $\&$ others
More collective (including teammates)

More collective (including teammates)

More collective (including

teammates)
0.43

Language prime (Assume English as individualism prime; Chinese, Cebuano, or Nepali as collectivism prime)

Kemmelmeier \& Cheng $(2004)$

126 Hong Kong Chinese

SCS (Singelis,

More independent

More interdependent (96 college, 30 middle 1994)

$\&$ collective

school) students (63

English, 63 Chinese)

Ross et al. (2002)

52 Chinese (mostly Hong Kong Chinese) in Canada (29 English,

TST modified;
Self-Esteem 23 Chinese $)^{\mathrm{a}}$

Scale (Rosenberg, 1965)

Trafimow et al. (1997)

152 Hong Kong Chinese college and high school students (76 English, 76 Chinese)

Watkins \& Gerong (1999)

166 high school (age $M$ $=16)$ Filipino students (83 English, 83 Cebuano) TST

(n)

TST

171 Nepali (age $M=24$ ) TST (98 English, 73 Nepali)
More independent self- More interdependent descriptions; higher \& collective selfself-esteem descriptions; lower self-esteem

More independent self- More collective selfdescriptions descriptions

More independent self- More interdependent descriptions \& collective (both small- \& largegroup) selfdescriptions

More independent self- More interdependent \& collective (both small- \& largegroup) selfdescriptions

Note. Participants are described in the detail available in the published article; where only country is known, this information is provided (e.g., U.S.). If the sample is described with regard to race/ethnicity (e.g., European American), this information is provided. TST = Twenty Statements Task (Kuhn \& McPartland, 1954); SCS = Self-Construal Scales (Leung \& Kim, 1997, unless specified otherwise); SDFF = similarities and differences with family and friends task.

${ }^{\text {a }}$ Only Chinese-born participants $(n=52)$ were language-primed (English vs. Chinese) and included in computing the language prime effect. Canadian data were excluded. 
Table A3

Relationality Studies Used in the Meta-Analysis

\begin{tabular}{|c|c|c|c|c|c|}
\hline $\begin{array}{l}\text { Studies organized by } \\
\text { priming task and level } \\
\text { of collectivism primed }\end{array}$ & $\begin{array}{l}\text { Sample is undergraduates } \\
\text { unless otherwise specified } \\
\text { (Language) }\end{array}$ & Measure & $\begin{array}{l}\text { Expected individualism } \\
\text { prime effect }\end{array}$ & $\begin{array}{c}\text { Expected collectivism prime } \\
\text { effect }\end{array}$ & $\begin{array}{l}\text { Effect size } \\
\quad(d)\end{array}$ \\
\hline \multicolumn{6}{|c|}{ European heritage } \\
\hline \multicolumn{6}{|c|}{ Relational collectivism } \\
\hline $\begin{array}{l}\text { Pronoun circling task } \\
\text { Gardner et al. (2004) }\end{array}$ & $\begin{array}{l}24 \text { European Americans } \\
\text { (English) }\end{array}$ & Social obligation & More self-oriented & More group-oriented & 0.74 \\
\hline $\begin{array}{l}\text { Gardner et al. (1999, } \\
\text { Study 1) }\end{array}$ & $\begin{array}{l}45 \text { European Americans } \\
\text { (English) }\end{array}$ & $\begin{array}{l}\text { Perceived social obligation } \\
\text { to help (Miller et al., } \\
\text { 1990) }\end{array}$ & Weaker & Stronger & 0.74 \\
\hline $\begin{array}{l}\text { Kemmelmeier ( } 2003 \text {, } \\
\text { Study 1) }\end{array}$ & $\begin{array}{l}48 \text { U.S. (34 European } \\
\text { American) (English) }\end{array}$ & Justice preferences & $\begin{array}{l}\text { Favoring equal } \\
\text { opportunity }\end{array}$ & Favoring affirmative action & 0.60 \\
\hline Utz (2004a, Study 1) & $\begin{array}{l}68 \text { Dutch college } \\
\text { students (Dutch) }\end{array}$ & Prosocial choices & Fewer & More & 0.06 \\
\hline \multicolumn{6}{|l|}{ SDFF task } \\
\hline $\begin{array}{l}\text { Holland et al. (2004, } \\
\text { Study 2) }\end{array}$ & 27 Dutch (Dutch) & $\begin{array}{l}\text { Number chairs between } \\
\text { participant's and an } \\
\text { ostensibly occupied one }\end{array}$ & Farther apart & Closer together & 0.85 \\
\hline $\begin{array}{l}\text { Vohs \& Heatherton } \\
\text { (2001, Study } 3)\end{array}$ & $\begin{array}{l}23 \text { U.S. women } \\
\text { (English) }\end{array}$ & $\begin{array}{l}\text { Others' liking of } \\
\text { participant }\end{array}$ & Lower & Higher & 1.19 \\
\hline \multicolumn{6}{|c|}{ SDFF-based task: Personalized paragraph reading; purchase recall writing; sentence-with-keywords writing } \\
\hline $\begin{array}{l}\text { Kemmelmeier (2003, } \\
\text { Study 2) }\end{array}$ & $\begin{array}{l}54 \text { U.S. (44 European } \\
\text { Americans, } 5 \text { Asian } \\
\text { Americans) (English) }\end{array}$ & $\begin{array}{l}\text { Favorable response to } \\
\text { affirmative action }\end{array}$ & Less & More & 0.72 \\
\hline $\begin{array}{l}\text { Mandel }(2003 \text {, } \\
\text { Study 1) }\end{array}$ & 53 U.S. (English) & $\begin{array}{l}\text { Felt support; avoidance of } \\
\text { social risk }\end{array}$ & Weaker & Stronger & 0.52 \\
\hline \multicolumn{6}{|c|}{ Sumerian warrior story (mixed relational and collective group) } \\
\hline $\begin{array}{l}\text { Gardner et al. (1999, } \\
\text { Study 1) }\end{array}$ & $\begin{array}{l}45 \text { U.S. European } \\
\text { Americans (English) }\end{array}$ & $\begin{array}{l}\text { Perceived social obligation } \\
\text { to help (Miller et al., } \\
\text { 1990) }\end{array}$ & Weaker & Stronger & 0.74 \\
\hline $\begin{array}{l}\text { Mandel (2003, } \\
\text { Study 1) }\end{array}$ & 53 U.S. (English) & $\begin{array}{l}\text { Felt support; avoidance of } \\
\text { social risk }\end{array}$ & Weaker & Stronger & 0.52 \\
\hline
\end{tabular}

Scrambled sentence task

$\begin{array}{ll}\text { Utz (2004b) } & 63 \text { Germans (German) } \\ & \\ \text { van Baaren et al. } & 32 \text { Dutch (English) } \\ \quad \text { (2003, Study 2) } & \\ \begin{array}{l}\text { Unclassified task } \\ \text { Wenzel (2002, } \\ \text { Study 2) }\end{array} & 49 \text { Germans (German) } \\ \begin{array}{l}\text { Mandel (2003, pilot } \\ \text { study) }\end{array} & 89 \text { U.S. (English) }\end{array}$

Both relational and collective group-based collectivism

$\begin{array}{llll}\begin{array}{c}\text { Cooperation \& goal in } \\ \text { game }\end{array} & \begin{array}{c}\text { Less cooperative, own- } \\ \text { gain goal } \\ \text { Limicking }\end{array} & \begin{array}{l}\text { More cooperative, other- } \\ \text { gain goal } \\ \text { Less }\end{array} & 0.30 \\ & \text { More } & 0.98\end{array}$

\section{Social obligation (entitlement judgments)}

Product choice; risk-taking gain goal

Less
More group-value-based (willing to give to prototypical member)
Less willing to take financial risk
More

0.98

More self-interest (willing to give to self)

More willing to take financial risk

32

Russian American heritage
Language prime (Assume English as individualism prime; Russian as collectivism prime)

\begin{tabular}{ll} 
Marian \& & 47 Bilingual Russian \\
Kaushanskaya & American adults (age \\
(2004) & $M=21 ;$ \\
& within-subjects: half in \\
& Russian, half in \\
& English) \\
\hline
\end{tabular}

Asian North American heritag

Relational collectivism

Pronoun circling task

Gardner et al. (2004)
More personal, lower centrality of others higher $\%$ personal pronouns, lower \% group pronouns
More relational, higher centrality of others, lower $\%$ personal pronouns, higher $\%$ group pronouns

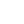

30


Table A4

Well-Being Studies Used in the Meta-Analysis

\begin{tabular}{ccccc}
\hline $\begin{array}{c}\text { Studies organized by } \\
\text { priming task and } \\
\text { level of collectivism } \\
\text { primed }\end{array}$ & $\begin{array}{c}\text { Sample is } \\
\text { undergraduates unless } \\
\text { otherwise specified } \\
\text { (Language) }\end{array}$ & Measure & $\begin{array}{c}\text { Expected individualism } \\
\text { prime effect }\end{array}$ & $\begin{array}{c}\text { Expected collectivism } \\
\text { prime effect }\end{array}$ \\
\hline & \multicolumn{3}{c}{$\begin{array}{c}\text { Effect } \\
\text { size } \\
(d)\end{array}$} \\
\hline
\end{tabular}

Both relational and collective group-based collectivism

\begin{tabular}{|c|c|c|c|c|}
\hline $\begin{array}{l}\text { Sumerian warrior stor } \\
\text { Gardner et al. (2002, } \\
\text { Study 2) }\end{array}$ & 82 U.S. (English) & $\begin{array}{l}\text { Mood (McFarland \& } \\
\text { Beuhler, 1995) in } \\
\text { face of mismatch } \\
\text { between own and } \\
\text { group performance }\end{array}$ & $\begin{array}{l}\text { Feeling good when } \\
\text { own performance } \\
\text { good }\end{array}$ & $\begin{array}{l}\text { Feeling good when } \\
\text { group performance } \\
\text { good }\end{array}$ \\
\hline \multicolumn{5}{|c|}{ Subliminal priming task (mixed relational and collective group) } \\
\hline $\begin{array}{l}\text { Oishi et al. ( } 2000 \text {, } \\
\text { Study } 3)\end{array}$ & $\begin{array}{l}40 \text { European Americans } \\
\text { (English) }\end{array}$ & $\begin{array}{l}\text { Correlation between } \\
\text { current life } \\
\text { satisfaction \& } \\
\text { future outlook }\end{array}$ & Higher & Lower \\
\hline
\end{tabular}

Group imagination task (solo vs. team tennis match)

Lee et al. (2000, 215 U.S. (English)
Study 5)

Collective group-based collectivism

\begin{tabular}{|c|c|c|c|c|c|}
\hline $\begin{array}{l}\text { Lee et al. (2000, } \\
\text { Study 5) }\end{array}$ & 215 U.S. (English) & $\begin{array}{l}\text { Emotions (PANAS; } \\
\text { Watson et al., } \\
\text { 1988) }\end{array}$ & $\begin{array}{l}\text { More likely to feel } \\
\text { dejection- elation } \\
\text { emotions }\end{array}$ & $\begin{array}{l}\text { More likely to feel } \\
\text { agitation- } \\
\text { quiescence } \\
\text { emotions }\end{array}$ & -0.68 \\
\hline \multicolumn{6}{|c|}{ Language prime (Assume English as individualism prime; Chinese as collectivism prime) } \\
\hline Ross et al. (2002) & $\begin{array}{l}52 \text { Chinese (mostly } \\
\text { Hong Kong Chinese) } \\
\text { in Canada (29 } \\
\text { English, } 23 \text { Chinese) }^{\text {a }}\end{array}$ & $\begin{array}{l}\text { Mood (PANAS; } \\
\text { Watson et al., } \\
\text { 1988) }\end{array}$ & Heightened & Dampened & 0.54 \\
\hline
\end{tabular}

Asian North American heritage

\begin{tabular}{|c|c|c|c|c|c|}
\hline \multicolumn{6}{|c|}{ Asian heritage } \\
\hline $\begin{array}{l}\text { Group imagination task } \\
\text { Lee et al. (2000, } \\
\quad \text { Study 5) }\end{array}$ & $\begin{array}{l}\text { olo vs. team tennis mat } \\
312 \text { Hong Kong } \\
\text { Chinese (English) }\end{array}$ & $\begin{array}{l}\text { Emotions (PANAS; } \\
\text { Watson et al., } \\
\text { 1988) }\end{array}$ & $\begin{array}{l}\text { More likely to feel } \\
\text { dejection- elation } \\
\text { emotions }\end{array}$ & $\begin{array}{l}\text { More likely to feel } \\
\text { agitation-- } \\
\text { quiescence } \\
\text { emotions }\end{array}$ & -0.15 \\
\hline
\end{tabular}

Note. Participants are described in the detail available in the published article; where only country is known, this information is provided (e.g., U.S.). If the sample is described with regard to race/ethnicity (e.g., European American), this information is provided. PANAS = Positive and Negative Affect Schedule.

${ }^{a}$ Only Chinese-born participants ( $n=52$ ) were language-primed (English vs. Chinese) and included in computing the language prime effect. Canadian data were excluded. 
Table A5

Cognition Studies Used in the Meta-Analysis

\begin{tabular}{|c|c|c|c|c|}
\hline $\begin{array}{l}\text { Studies organized by } \\
\text { priming task and } \\
\text { level of collectivism } \\
\text { primed }\end{array}$ & $\begin{array}{c}\text { Sample is } \\
\text { undergraduates unless } \\
\text { otherwise specified } \\
\text { (Language) }\end{array}$ & Measure & $\begin{array}{l}\text { Expected individualism } \\
\text { prime effect }\end{array}$ & $\begin{array}{l}\text { Expected collectivism } \\
\text { prime effect }\end{array}$ \\
\hline
\end{tabular}

European heritage

Relational collectivism

Pronoun circling task

Haberstroh et al. (2002, Study 1)

34 Germans (German) Sensitivity to conversational norm

Haberstroh et al. (2002, Study 2

pretest)

Kühnen \& Haberstroh (2004)

213 Germans

(German)

Kühnen et al. (2001， 30 U.S. (English) Study 4)

Kühnen \&

Oyserman $(2002$

Study 1)

Kühnen \& Oyserman (2002,

Study 2)

Stapel \& Koomen (2001, Study 1)

Stapel \& Koomen (2001, Study 5)

SDFF task

Kühnen et al. (2001， 51 German (German) Study 1)

30 U.S. (English)

34 U.S. (English)

144 Dutch (Dutch)

Difference between self $\rightarrow$ target and target $\rightarrow$ self comparisons

Number of correctly identified figures in Embedded Figures Test (Horn, 1962)

Response latency in recognizing gestalt (big letter made of small letters) and components (small letters)

Memory for items and their placement in a grid (Chalfonte \& Johnson, 1996)

Social comparison (self-evaluation)

Social comparison (self-evaluation; perceived importance of task)

Response latency in Embedded Figures Test (Witkin et al., 1971)

Kühnen et al. (2001, 76 German (German) Study 2)

Number of correctly identified figures in Embedded Figures Test (Horn, 1962)

Kühnen et al. (2001, 52 German (German) Study 3)

Number of correctly solved missing picture items in Hamburg-Wechsler Intelligence Test (Tewes, 1994)

Ybarra \& Trafimow 60 U.S. (English)

Focus of decision-making regarding condom use intention
60 Dutch (Dutch)
Higher correlation between responses to redundant questions

Higher correlation between responses to redundant questions

Contrast; more selfreferent independent)

Quicker componential (contextindependent) processing

Worse memory for placement (less context-dependent)

Contrast

Contrast

Quicker (more contextindependent)

More (more contextindependent)

Fewer (less contextdependent)

On personal attitudes

On norms

Stronger for prevention-focused message

Lower correlation between responses to redundant questions

Lower correlation between responses to redundant questions

Assimilation; less self-referent

Fewer (less contextindependent)

Quicker gestalt (contextdependent) processing

Better memory for placement (more context-dependent)

Assimilation

Assimilation

Slower (less contextindependent)

Fewer (less contextindependent)

More (more contextdependent)

promotion-focused message
More (more context-

Persuasion, immediate and delayed brand affinity
Group imagination task (imagining self vs. family)

Aaker \& Lee (2001, 92 European Study 1)

Americans

(English)

Both relational and collective group-based collectivism

Sumerian warrior story

Gardner et al. (2002, 59 U.S. (English) Study 1)

Ybarra \& Trafimow (1998, Study 2)

Ybarra \& Trafimow (1998, Study 3) 48 U.S. (English) 52 U.S. (English)

Task based on scra

Briley \& Wyer (2001, Study 4)

Kühnen \& Hannover (2000)

Lockwood et al. (2004, Study 2)
64 Canadian (English) regarding condom use intention
bled sentence: Priming with specific words

Predicted good friend's performance on self-relevant task

Focus of decision-making regarding condom use intention

Focus of decision-making

Proportion of choices that are compromise choice

Perceived similarity of self to other

Relationship-relevant selfappraisals
Worse (contrast other to self)

On personal attitudes

On personal attitudes

Better (modesty, join

0.79 other with self)

On norms

On norms

Lower

Higher

Lower (differentiation)

Higher (assimilation)

$-0.00$

Worse

Better

Worse

(d) 
Table A5 (continued)

\begin{tabular}{|c|c|c|c|c|c|}
\hline $\begin{array}{l}\text { Studies organized by } \\
\text { priming task and } \\
\text { level of collectivism } \\
\text { primed }\end{array}$ & $\begin{array}{c}\text { Sample is } \\
\text { undergraduates unless } \\
\text { otherwise specified } \\
\text { (Language) }\end{array}$ & Measure & $\begin{array}{l}\text { Expected individualism } \\
\text { prime effect }\end{array}$ & $\begin{array}{l}\text { Expected collectivism } \\
\text { prime effect }\end{array}$ & Effect size $(d)$ \\
\hline \multicolumn{6}{|c|}{ Subliminal priming, paragraph writing task } \\
\hline $\begin{array}{l}\text { Oishi et al. (2000, } \\
\text { Study 3) }\end{array}$ & $\begin{array}{c}40 \text { European } \\
\text { Americans (English) }\end{array}$ & $\begin{array}{l}\text { Preference of attribution for } \\
\text { another's success or failure }\end{array}$ & Dispositional & Situational & 0.43 \\
\hline $\begin{array}{l}\text { Stapel \& Koomen } \\
\quad(2001, \text { Study } 2)^{\mathrm{a}}\end{array}$ & 160 Dutch (Dutch) & $\begin{array}{l}\text { Social comparison (self-evaluation, } \\
\text { perceived similarity) }\end{array}$ & Contrast & Assimilation & 1.43 \\
\hline \multicolumn{6}{|c|}{ Collective group-based collectivism } \\
\hline $\begin{array}{c}\text { Aaker \& Lee (2001, } \\
\text { Study 2) }\end{array}$ & $\begin{array}{l}118 \text { European } \\
\text { Americans (English) }\end{array}$ & Scenario recall & $\begin{array}{l}\text { Better for promotion- } \\
\quad \text { focus scenario }\end{array}$ & $\begin{array}{l}\text { Better for prevention- } \\
\text { focus scenario }\end{array}$ & 0.42 \\
\hline $\begin{array}{c}\text { Aaker \& Lee (2001, } \\
\text { Study 3) }\end{array}$ & $\begin{array}{l}177 \text { European } \\
\text { Americans (English) }\end{array}$ & $\begin{array}{l}\text { Sensitivity to strong vs. weak } \\
\text { arguments }\end{array}$ & $\begin{array}{l}\text { Stronger for } \\
\text { promotion-focus } \\
\text { scenario }\end{array}$ & $\begin{array}{l}\text { Stronger for } \\
\text { prevention-focus } \\
\text { scenario }\end{array}$ & 1.08 \\
\hline
\end{tabular}

Asian North American heritage

Subliminal priming, paragraph writing task

23 Asian Americans Study 3) (English)

\section{Both relational and collective group-based collectivism}

Preference of attribution for another's success or failure

Dispositional

Situational

Asian heritage

Both relational and collective group-based collectivism

Task based on scrambled sentence: Priming with specific words

\begin{tabular}{|c|c|c|c|c|}
\hline $\begin{array}{l}\text { Adaval \& Cho } \\
\text { (2006, Study 1, } \\
\text { unpublished data }\end{array}$ & $\begin{array}{l}116 \text { Hong Kong } \\
\text { Chinese (English) }\end{array}$ & Liking for Pepsi ad & $\begin{array}{l}\text { Preferring difference } \\
\text { ("stand out from the } \\
\text { crowd") }\end{array}$ & $\begin{array}{l}\text { Preferring sameness } \\
\text { ("don't stand out } \\
\text { from the crowd") }\end{array}$ \\
\hline
\end{tabular}

from the crowd")

0.42

reported in Briley

\& Wyer, 2002)

Briley \& Wyer

(2001, Study 4)

29 Hong Kong

Chinese (English)
Proportion of choices that are compromise choice

Lower Higher

0.38

\section{Collective group-based collectivism}

Group instantiation task (sitting separated from others, scored individually vs. sitting in a group, giving it a name, scored as a group)

Briley \& Wyer 43 Hong Kong Compromise choice (one of each Less likely More likely

(2002, Study 2) Chinese (English) rather than two of the same candy)

Briley \& Wyer 93 Hong Kong Compromise choice (one of each

(2002, Study 3) Chinese (English) rather than two of the same candy)

Group imagination task (imagining solo vs. team tennis match)

Aaker \& Lee (2001, 95 Hong Kong Scenario recall Study 2)

Chinese (English)

83 Hong Kong

Aaker \& Lee (2001,

Chinese (English)

Liking for brand with strong argument

Less likely

More likely Study 4)

Language prime (Assume English as individualism prime; Chinese as collectivism prime)

$\begin{array}{ccc}\text { Tavassoli (2002, } & 41 \text { Singaporeans (21 } & \begin{array}{c}\text { Recognition of placement of } \\ \text { Study 3) }\end{array} \\ \text { English, 20 Chinese }) & \text { nonsense words }\end{array}$
Better for promotion- focused scenario
Stronger for
promotion-focused scenario
Better for prevention- focused scenario
Stronger for prevention-focused

scenario Study 3) English, 20 Chinese) nonsense words

Worse

Better

Note. Participants are described in the detail available in the published article; where only country is known, this information is provided (e.g., U.S.). If the sample is described with regard to race/ethnicity (e.g., European American), this information is provided. SDFF $=$ similarities and differences with family and friends task.

${ }^{a}$ Participants were primed by writing a paragraph with pronouns (I, me, myself, mine vs. we, our, ourselves, ours) and specific words (unique, special, unusual vs. together, integrate, harmony). 